\title{
Identification of Structural Calcium Binding Sites in Membrane-Bound Presenilin 1 and
} 2

Mehra, Rukmankesh; Identification of Structural Calcium Binding, Kasper

Published in:

Journal of Physical Chemistry Part B: Condensed Matter, Materials, Surfaces, Interfaces \& Biophysical

Link to article, DOI:

10.1021/acs.jpcb.0c01712

Publication date:

2020

Document Version

Peer reviewed version

Link back to DTU Orbit

Citation (APA):

Mehra, R., \& Identification of Structural Calcium Binding, K. (2020). Identification of Structural Calcium Binding Sites in Membrane-Bound Presenilin 1 and 2. Journal of Physical Chemistry Part B: Condensed Matter Materials, Surfaces, Interfaces \& Biophysical, 124(23), 4697-4711. https://doi.org/10.1021/acs.jpcb.0c01712

\section{General rights}

Copyright and moral rights for the publications made accessible in the public portal are retained by the authors and/or other copyright owners and it is a condition of accessing publications that users recognise and abide by the legal requirements associated with these rights.

- Users may download and print one copy of any publication from the public portal for the purpose of private study or research.

- You may not further distribute the material or use it for any profit-making activity or commercial gain

- You may freely distribute the URL identifying the publication in the public portal 


\section{B: Biophysics; Physical Chemistry of Biological Systems and Biomolecules}

\section{Identification of Structural Calcium Binding Sites in Membrane-Bound Presenilin 1 and 2}

Rukmankesh Mehra, and Kasper P. Kepp

J. Phys. Chem. B, Just Accepted Manuscript • DOI: 10.1021/acs.jpcb.0c01712 • Publication Date (Web): 18 May 2020

Downloaded from pubs.acs.org on May 25, 2020

\section{Just Accepted}

"Just Accepted" manuscripts have been peer-reviewed and accepted for publication. They are posted online prior to technical editing, formatting for publication and author proofing. The American Chemical Society provides "Just Accepted" as a service to the research community to expedite the dissemination of scientific material as soon as possible after acceptance. "Just Accepted" manuscripts appear in full in PDF format accompanied by an HTML abstract. "Just Accepted" manuscripts have been fully peer reviewed, but should not be considered the official version of record. They are citable by the Digital Object Identifier (DOI®). "Just Accepted" is an optional service offered to authors. Therefore, the "Just Accepted" Web site may not include all articles that will be published in the journal. After a manuscript is technically edited and formatted, it will be removed from the "Just Accepted" Web site and published as an ASAP article. Note that technical editing may introduce minor changes to the manuscript text and/or graphics which could affect content, and all legal disclaimers and ethical guidelines that apply to the journal pertain. ACS cannot be held responsible for errors or consequences arising from the use of information contained in these "Just Accepted" manuscripts. 


\title{
Identification of Structural Calcium Binding Sites in Membrane-Bound Presenilin 1 and 2
}

\author{
Rukmankesh Mehra and Kasper P. Kepp* \\ Technical University of Denmark, DTU Chemistry, DK-2800 Kongens Lyngby, Denmark \\ *Correspondence: Email: kpj@,kemi.dtu.dk
}

\begin{abstract}
Variants of presenilin (PS1 and PS2) are the main genetic risk factors of familial Alzheimer's disease and thus central to the disease etiology. Although mostly studied as catalytic units of $\gamma$ secretase controlling $A \beta$ production, presenilins also affect calcium levels, which are disturbed in Alzheimer's disease. We investigated the interaction of calcium with both PS1 and PS2 using allatom molecular dynamics (MD) simulations in realistic membrane models, with the specific aim to identify any $\mathrm{Ca}^{2+}$ sites. We did not observe any complete $\mathrm{Ca}^{2+}$ leak event, but we identified four persistent $\mathrm{Ca}^{2+}$ sites in membrane-bound PS1 and PS2: One in HL2 near the C-terminal of TM6, one in HL2 towards the N-terminal of TM7, a site at the catalytic aspartate on TM7, and a site at the PALP motif on TM9. The sites feature negatively charged glutamates and aspartates typical of calcium binding. Structural homology to di-aspartate calcium transport proteins and mutation studies of calcium efflux support our identified calcium sites. Calcium consistently dampens HL2 motions in all comparisons (PS1, protonated PS1, PS2, protonated PS2). Due to their location in HL2 and the active site, we propose that the calcium sites control auto-proteolytic maturation of presenilin by a pH-dependent conformational restriction of the HL2 recognition loop, which also regulates calcium transport proteins such as inositol 1,4,5-triphosphate receptor and ryanodine receptor. Our structural dynamics could provide a possible molecular basis for the need of both calcium and presenilin for lysosome proteolytic function, perhaps relevant also to other protein misfolding diseases.
\end{abstract}




\section{Introduction}

Alzheimer's disease (AD), the major neurodegenerative disease and most common form of ageinduced dementia, affects perhaps 30-40 million people world-wide. ${ }^{1-3}$ It is associated with gradual impairment of memory, cognitive skills, identity, activities of daily living, and life quality $^{4,5}$ and is thus terrible to both patients and relatives and puts a heavy strain on healthcare budgets. ${ }^{16}$ Because of its very complex molecular etiology and the complexity of its target, the aging human brain, current treatments on the market are mainly symptom-relieving. ${ }^{1,7,8}$ Recent attempts to develop causal medicine based on the amyloid hypothesis, i.e. the assumption that $\beta$ amyloid (A $\beta$ ) alone causes the disease, ${ }^{9,10}$ have failed, leading to a large surge in research that reexamines the fundamental assumptions and alternative explanations of the disease. ${ }^{11-21}$

The histopathological basis for the amyloid hypothesis is the consistent presence of senile plaques in the affected brains, which led to the original hypothesis that these plaques cause AD. ${ }^{22}$ The mechanistic basis is the cellular toxicity of $A \beta$ and its effect on transgenic rodents. ${ }^{23}$ The genetic basis is that mutations in the genes of the $\beta$-amyloid precursor protein (APP) ${ }^{24}$ and the two homologous proteins presenilin 1 (PS1) and presenilin 2 (PS2) ${ }^{25-29}$ cause a small minority of earlyonset familial AD (fAD). A $\beta$ is produced from APP upon cleavage by $\beta$ - and $\gamma$-secretases, ${ }^{30,31}$ and presenilin is the catalytic subunit of the $\gamma$-secretase complex, ${ }^{32-34}$ which cleaves many type-I transmembrane helical substrates, including Notch. ${ }^{35,36}$

After cleavage by $\beta$-secretase, the remaining C-terminal fragment C99 is cleaved in the membrane by $\gamma$-secretase, thereby releasing $A \beta$ of various lengths, most notably $A \beta_{40}$ and the more hydrophobic, aggregation-prone, and toxic $A \beta_{42}$. Most mutations in PS1 and PS2 tend to impair the activity of $\gamma$-secretase, lower the total production of $A \beta$ and at the same time increase the relative ratio $A \beta_{42} / A \beta_{40},{ }^{28,37,38}$ this ratio correlates with the clinical severity of the variant in patients ${ }^{39}$, making it a central phenotypic relationship for understanding the disease.

One of the most prominent alternative hypotheses of $\mathrm{AD}$ is that calcium $\left(\mathrm{Ca}^{2+}\right)$ dysregulation causes $\mathrm{AD}$, as proposed more than 30 years ago..$^{40}$ There is massive evidence that $\mathrm{AD}$ features disturbed calcium homeostasis, ${ }^{41-45}$ and presenilin plays a significant role in controlling $\mathrm{Ca}^{2+}$ in the endoplasmic reticulum (ER) and cytoplasm. ${ }^{46-51}$ Some literature has suggested that immature presenilins, which generally localize in the membrane of the ER, form low-conductance $\mathrm{Ca}^{2+}$ leak pores. ${ }^{41}$ Structural evidence supports the presence of a channel morphology in PS1 that coincides with the active site. ${ }^{52} \mathrm{We}$ also note that PS1 features fascinating structural homology with some di-aspartate transmembrane calcium transport proteins, whose $\mathrm{pH}$-dependent Asp protonation controls open and closed states. ${ }^{53}$ It is notable that both an increased $A \beta_{42} / A \beta_{40}$ ratio and perturbed intracellular calcium levels are consistent features of PS1/PS2 fAD mutations, ${ }^{54-56}$ which could 
indicate that the active site of PS1/PS2 somehow affects the calcium regulatory function, and we speculate that the two mechanisms are in fact related via a physiological purpose.

The direct role of presenilin as a $\mathrm{Ca}^{2+}$ leak has been refuted by several groups. ${ }^{57-60}$ There is however agreement that overexpression of fAD mutants increases $\mathrm{Ca}^{2+}$ efflux from $\mathrm{ER}$ in the absence of high $\mathrm{Ca}^{2+}$ concentration in the ER lumen. ${ }^{58-60}$ This attracts attention towards other wellknown ER $\mathrm{Ca}^{2+}$ leak channels. Presenilin mutations affect the activity of the inositol 1,4,5triphosphate receptor (IP3R) and ryanodine receptor (RyR), thereby regulating $\mathrm{Ca}^{2+}$ indirectly.43,46,49,61 Presenilin also appears to regulate $\mathrm{Ca}^{2+}$ transport by sarcoendoplasmic reticulum calcium ATPase (SERCA). ${ }^{62}$ These reports together establish consensus that presenilin regulates ER calcium levels independent of $\gamma$-secretase activity and that fAD-linked mutations change $\left[\mathrm{Ca}^{2+}\right]$ in the ER lumen and disturb $\mathrm{Ca}^{2+}$ leak upon cell stimulus. ${ }^{56,63}$ However, the structural basis for presenilin's regulation of $\left[\mathrm{Ca}^{2+}\right]$ is completely unknown.

In the present study, we investigated the interaction of calcium with both PS1 and PS2 using all-atom molecular dynamics (MD) simulations in realistic membrane models, with the specific aim to identify the structural basis for any $\mathrm{Ca}^{2+}$ transport or regulation. Since protonation states play a role in structurally similar di-aspartate calcium transporters, ${ }^{53}$ we also investigated the protonation state of the catalytic aspartate on TM6, which is by far the most likely to be protonated according to our study. 


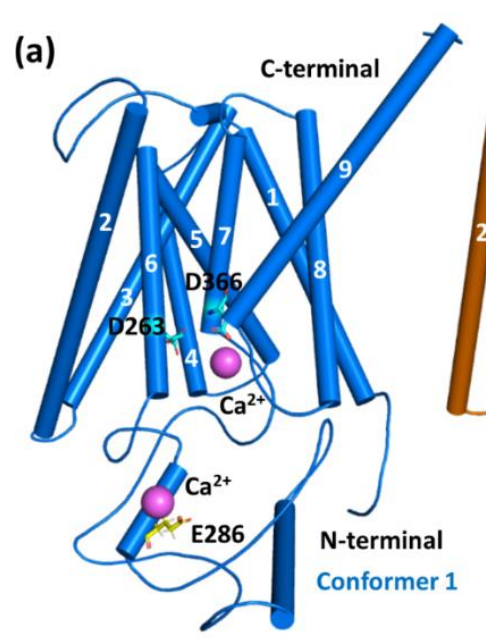

(b)

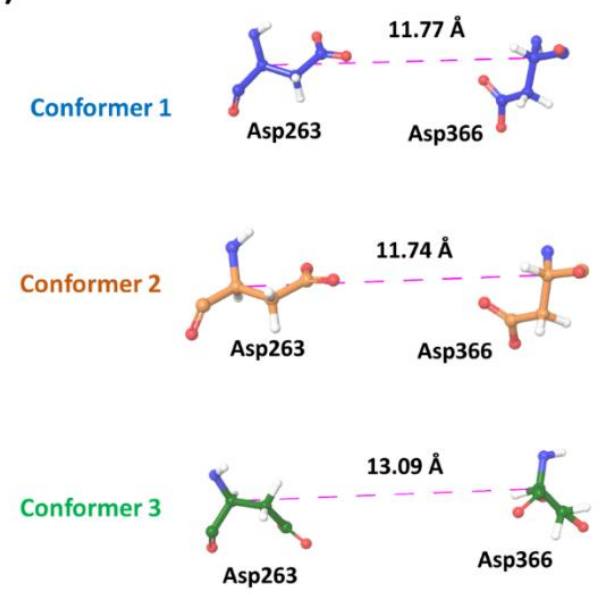

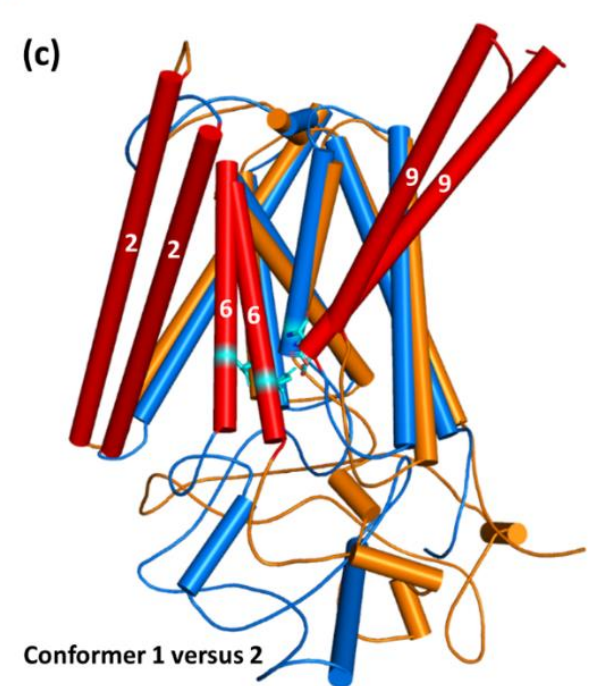

(d) 71 EELTLKYGAKHVIMLFVPVTLCMVVVVATIKSVSFYTRKDGOLIYTPFTEDTETVGORALHSILNAAIMISVIVVMTILLVVL 153

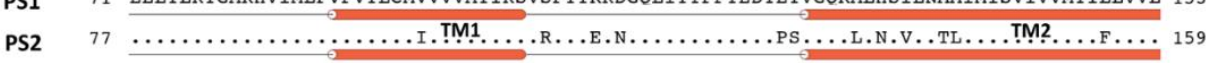

$$
\begin{aligned}
& \text { PS1 } 154 \text { YKYRCYKVIHAWLIISSLLLLFFFSFIYLGEVFKTYNVAVDYITVALLIWNFGVVGMISIHWKGPLRLOOAYLIMISALMALV } 236
\end{aligned}
$$

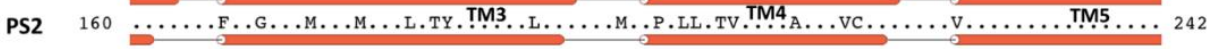

$$
\begin{aligned}
& \text { PS1 } 237 \text { FIKYLPEWTAWLILAVISVYDLVAVLCPKGPLRMLVETAOERNETLFPALIYSSTMVWLVNMAEGDPEAORRVSKNSKYNAES } 319
\end{aligned}
$$

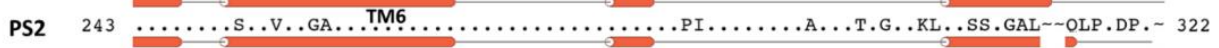

$$
\begin{aligned}
& \text { PS1 } 320 \text { TERESODTVAENDDGGFSEEWEAORDSHLGPHRSTPESRAAVOELSSSILAGEDPEERGVKLGLGDFIFYSVLVGKASATASG } 402
\end{aligned}
$$

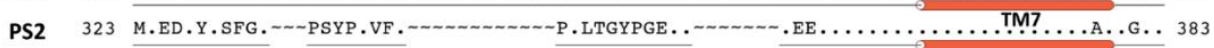

$$
\begin{aligned}
& \text { PS1 } 403 \text { DWNTTIACFVAILIGLCLTLLLLAIFKKALPALPISITFGLVFYFATDYLVOPFMDOLAFHOFYI } 467 \\
& \text { PS2 } 384 \ldots \ldots \text { L....TM8 } 8 \ldots \ldots \text {. }
\end{aligned}
$$

Fig. 1 Structural models and sequences of PS1 and PS2. (a) Compact (blue and orange) and open (green) PS2 conformations from previous cluster analysis ${ }^{64}$ used as models for the present work. Catalytic aspartates are shown as cyan sticks. Two possible $\mathrm{Ca}^{2+}$ sites are shown as purple spheres: one in the catalytic site (D263 and D366) and another in HL2 (E286, E357 and E325 in states 1, 2 and 3). Only one $\mathrm{Ca}^{2+}$ was during simulation. (b) The distance between $\mathrm{C} \alpha$ atoms of catalytic Asp263-Asp366 in the three structures. (c) Superimposition of the compact states 1 and 2, with distinct transmembrane segments colored red. (d) PS1 and PS2 sequences showing the TM1-TM9 helical segments. Residues that are identical in PS2 and PS1 are represented by dots. The TM9 kink (P455 in PS1 and P436 in PS2) is specific to the open conformation (structure 3). 


\section{Methods}

\section{PS1 and PS2 models used as input}

Recently, we performed MD simulations of immature presenilin-2 (PS2) (without calcium) in a membrane model that revealed three important conformation states of the protein. ${ }^{64}$ The representative structures obtained from clustering analysis of the equilibrated trajectories, shown in Fig. 1, were used as the initial coordinates of calcium-associated PS2 in the current study. Two of the structures represent the compact conformation state of PS2 (conformers 1 and 2) and one features a distinctly more open active site (conformer 3 ), which is also associated with bending of TM9. 64

The two compact states had similar distances between the catalytic aspartates, while it was larger in the open state (Fig. 1b). The orientation of TM2, TM6 and TM9 differs in the two compact states (Fig. 1c), with TM2 more tilted inwards at the N-terminal in conformer 1 . The Cterminal of TM6 is oriented outwards in conformer 1 whereas it is oriented inward for conformer 2. Similarly, the C-terminal TM9 segment of conformer 1 is tilted more outwards than conformer 2. In addition, the HL2 conformation differed substantially in the two compact states.

In order to account for different conformation state effects on calcium binding and to ensure optimal and fair comparison of PS2 and PS1, we built three PS1 structures from these PS2 states by homology modeling using Modeller. ${ }^{65}$ PS1 and PS2 share a sequence identity of $\sim 77.4 \%$ (as calculated by Modeller) and the final PS1 models were selected based on the lowest value of DOPE score. ${ }^{66}$ We note that these models are in essential agreement with the available structural data from cryo-electron microscopy of the subunits in the full $\gamma$-secretase complex, as discussed previously. ${ }^{64,67}$

\section{Protonation states of catalytic aspartates}

The protonation states of the two catalytic aspartates of TM6 and TM7 may affect the protein function both alone and in the $\gamma$-secretase complex. ${ }^{68}$ To analyze whether protonation could affect $\mathrm{Ca}^{2+}$ binding or transport of immature presenilin, we analyzed the representative structures from 22 previous MD simulations of both immature and mature presenilin states at variable $\mathrm{pH}$ along with the experimental $\gamma$-secretase structures (Supplementary Tables S1-S2).

The PROPKA 3.1 program $^{69,70}$ was used to calculate the pKa values of the catalytic aspartates at $\mathrm{pH} 4.5,5,6,7$, and 8. The experimental structures of PS1 exist as the $\gamma$-secretase complex; therefore, we calculated the protonation states both for the complex and separately for presenilin. 
At physiological pH (7.4; i.e. 7-8), all experimental PDB structures of PS1 without substrate bound clearly favor a deprotonated state for both catalytic aspartates, except 5FN2 and 5FN3, which have a tendency towards protonated Asp385 (Table S2).

PS1 exists in mature form, with cleaved HL2, in these $\gamma$-secretase complexes and this loop is mostly not present in the experimental coordinates, yet the protonation of the catalytic aspartates could be influenced by the additional solvent accessibility caused by lack of this loop. Therefore, we also analyzed the simulated presenilin system both in mature and immature forms with complete modeled HL2 from previous work of our group (Table S1). ${ }^{64,67,71-74}$ We note that the MD structures carry bias in their $\mathrm{pK}_{\mathrm{a}}$ to the fixed protonation state of the systems, but the structures still give an idea of the role of conformations on $\mathrm{pK}_{\mathrm{a}}$ and they were thus included. At $\mathrm{pH} 7$ and 8 , we find that both catalytic aspartates are charged in all the $22 \mathrm{MD}$ equilibrated structures, in agreement with the estimates above based on the experimental structures. Only when reaching $\mathrm{pH}$ 6 , one of the two catalytic aspartates became protonated, but only within the complex, not in PS alone. When substrate is bound, we found that it is possible to protonate in several cases (Tables S1-S2). Our analysis of protonation states of PS and $\gamma$-secretase is the first complete of this type and shows clearly that the $\mathrm{pK}_{\mathrm{a}}$ of the two catalytic aspartates change substantially, by several $\mathrm{pK}_{\mathrm{a}}$ units, depending on the conformation state, loop conformation, and substrate binding, with a general tendency for the more solvent-accessible pockets to feature lower $\mathrm{pK}_{\mathrm{a}}$.

For PS2 alone of specific interest to the present study, at very acidic $\mathrm{pH}$, i.e. 4.5 and 5, Asp263 on TM6 tends to be protonated (two out of three PS2 structures show neutral Asp263 and charged Asp366). We used the three immature PS2 structures (Fig. 1) in the current study and built PS1 structures using them, and accordingly also studied two different protonation states of the catalytic aspartates - one with both aspartates in the charged state and another with one neutral aspartic acid on TM6 (Asp257 in PS1 and Asp263 in PS2). In all other aspects, the proteins were prepared and protonated according to physiological $\mathrm{pH} 7.4$ when preparing the all-atom models.

\section{Preparation of presenilin-calcium complexes}

Since the catalytic site is likely to be involved in the claimed $\mathrm{Ca}^{2+}$ leak function of presenilin, ${ }^{42}$ one $\mathrm{Ca}^{2+}$ was placed on the catalytic aspartate on TM7 (Asp385 on PS1 and Asp366 on PS2) using the candidate residue selection panel for ion placement in the Desmond program. ${ }^{75}$ This selection panel identifies the potential negatively charged sites on the protein using a positive probe (such as $\mathrm{Na}^{+}$). This procedure generated six complexes, representing three conformation states of both PS1 and PS2 with $\mathrm{Ca}^{2+}$ binding to the TM7-Asp and with a protonated TM6-Asp. In addition, the exact same six models were also studied without protonating the catalytic site, giving a total of 12 models of PS1 and PS2 with calcium bound in the catalytic pocket. 
Additionally, one $\mathrm{Ca}^{2+}$ was placed on the hydrophilic loop 2 (HL2) in the two protonation states, which generated six more complexes for each protein, for a total of 24 different systems. In this case, $\mathrm{Ca}^{2+}$ was placed at three different positions at HL2 of the three conformers to cover possible $\mathrm{Ca}^{2+}$ binding sites. The potential sites were identified by combining two approaches that included generating the electrostatic surfaces and then identifying candidate residues for positive ion binding (Fig. S1). These analyses were performed using the Maestro and Desmond modules of the Schrodinger software suite..$^{75}$

The transmembrane segments TM7 and TM9 are highly water accessible and have been claimed to be involved in calcium transport partly together with TM6. ${ }^{42,76}$ To maximize the chances of reproducing a transport event based on these observations, $\mathrm{Ca}^{2+}$ was placed on the potential candidate residue (preferably gluamate) in TM6, TM7, and TM9 at the pore/cavity of the catalytic site. For the three PS2 structures, these candidate residues included E286, E357, and E325, respectively, which are present in HL2 between TM6 and TM7. E286 is present near the Cterminal of TM6, whereas E357 lies near the N-terminal of TM7 and forms part of the extremely highly charged poly-glutamate stretch EELEEEEE (residues 350-357). For the three PS1 conformers, calcium was placed exactly at the same position as in PS2 after structural alignment, i.e. on E280, E376, and R322, respectively, to ensure optimal and fair comparison of the calcium dynamics of the two proteins.

\section{System preparation and MD simulations}

In order to build protein-membrane-water systems of each conformation and protonation state of PS1 and PS2, the initial alignment of the protein structure in the membrane model was done using the OPM-PPM server. ${ }^{77}$ First, the membrane-aligned presenilin models were inserted into a homogenous 1-palmitoyl-2-oleoylphosphatidylcholine (POPC) lipid bilayer using the CHARMM GUI server. ${ }^{78,79}$ To each membrane-protein system, TIP3P water molecules were added in a rectangular box. Use of systems without $\mathrm{NaCl}$ could potentially affect both the protein dynamics and the behavior of calcium since there are many more charged sodium and chloride ions than calcium ions in real systems, as also reflected by our simulations having one calcium ion per cell. Accordingly, we emulated a physiologically relevant $\mathrm{NaCl}$ concentration of $0.15 \mathrm{M}$ by randomly placing stoichiometric amounts of $\mathrm{Na}^{+}$and $\mathrm{Cl}^{-}$ions to reach a physiologically relevant ion concentration. The ions were placed outside the membrane region and their positions were identified by employing Monte Carlo simulations for 2000 steps using Coulombic (scaled by a dielectric constant of 80 ) and van der Walls interactions and a cut-off of $10 \AA$. The structurebalanced force field CHARMM36m was used to describe the proteins and ions. ${ }^{80}$ We note that absolute affinities and the ability to bind calcium at all will be force-field dependent, as this could 
affect the leakage propensity, but the relative ability to identify sites within the same protein should not be equally force-field dependent due to partial cancellation of over-binding or under-binding tendencies.

Molecular dynamics simulations were performed using Gromacs, version 2019.4. ${ }^{81,82}$ Each system was energy-minimized and pre-equilibrated using the standard six-step protocol as described in detail elsewhere, e.g. in our previous work. ${ }^{74}$ The first two phases of pre-equilibration included temperature coupling followed by two instances of temperature and pressure coupling, with each step spanning $25 \mathrm{ps}$ and using a time step of $1 \mathrm{fs}$. The final two steps occurred at constant temperature and pressure, each for $50000 \times 2$ ss. During equilibration, the temperature and pressure were maintained using the Berendsen method. ${ }^{83}$

The production simulations were performed for $1 \mu$ s for each system with a time-step of $2 \mathrm{fs}$. Three statistically independent conformers without protonation (Fig. 1) and three conformers with a protonated catalytic aspartate on TM6 were simulated for both PS1 and PS2 (12 systems) with $\mathrm{Ca}^{2+}$ placed near the catalytic aspartate on TM7. 12 corresponding simulations were performed with initial $\mathrm{Ca}^{2+}$ at $\mathrm{HL} 2$ as discussed above. Thus, in total, 24 simulations were performed, each for $1 \mu \mathrm{s}$, with triplicate independent simulation of each of eight different systems (2 protonation states $\mathrm{x} 2$ proteins $\mathrm{x} 2$ calcium sites) being carried out, to ensure that variation in outcome from different starting conformation states and velocities was well accounted for. During all simulations, the Nose-Hoover method ${ }^{84}$ was applied for maintaining temperature and the Parrinello-Rahman algorithm ${ }^{85}$ was used to ensure a constant ambient pressure of the system.

\section{Analysis of systems and dynamical trajectories}

The parameters of the membrane and water were analyzed over the full $1 \mu$ s trajectories, because we considered specifically non-equilibrium events of calcium binding and potential transport through the membrane, rather than efforts towards sampling equilibration. To this end, we calculated the partial densities of head, tail and phosphate groups of POPC and the properties of the TIP3P water molecules to check the consistency of the systems after and during simulation. The deuterium order parameters of the Sn1 and Sn2 chains of POPC were calculated as they provide a good measure of the average angular movement of these chains around the bilayer normal and thus probe the bilayer integrity.

The root-mean-squared deviation (RMSD), the radius of gyration $\left(\mathrm{R}_{\mathrm{g}}\right)$ and solvent accessible surface area (SASA) of each protein were analyzed with respect to the starting configurations over the full trajectories of all 24 systems. The distance between the candidate residues or catalytic aspartate and calcium was calculated. To test the impact of simulation time on our outcomes, we performed principal component analysis (PCA) and calcium interaction analysis both on the 
starting $500 \mathrm{~ns}(0-500 \mathrm{~ns})$ and the final parts of the trajectories (500-1000 ns). The center of mass of the molecule was put in the box and all the atoms were kept at the closest distance from the center of the box. For PCA analysis, all the structures were fitted to the reference structure (first frame structure). The PCA builds a covariance matrix of the atomic motion, and the resulting eigenvectors and eigenvalues define the collective motion of the protein, which are useful for identifying different major conformation states of the proteins.

The protein-calcium interactions were studied by calculating their distance using the "gmx mindist" utility of Gromacs. An interaction distance cutoff-off of $4 \AA$ was used and the percent interaction of each protein residue with calcium was calculated using the in-house Python code. All the plots were built using the Matplotlib library of Python 3. 


\section{Results and discussion}

\section{Realism of the total protein-membrane-water system}

To check the consistency of all the protein-membrane-water systems, we first calculated the deuterium order parameters of $\mathrm{Sn} 1$ and $\mathrm{Sn} 2$ fatty acid chains of glycerolipids in the POPC bilayer (Fig. S2). Both these acyl chains exhibit different conformations. The simulated systems showed excellent agreement with the experimentally known deuterium lipid orders. ${ }^{86}$ The Sn1 chain displayed a minimum for the third carbon and a maximum for carbons 5-6, and then a consistent decrease . Sn2 exhibited least movement at the tenth carbon and attained a double bump very similar to the experimental values. ${ }^{86}$

A detailed partial density analysis of the head, tail and phosphate groups of the POPC bilayer and TIP3P water molecules is summarized Fig. S3. The water density was high towards the edges of the systems and low in the middle, as the protein and POPC tail groups mainly occupied this part. Peripheral to this tail region, head and phosphate group were highly dense. These data are in excellent agreement with the standard values. ${ }^{74}$ From these various assessments, we conclude that the overall membrane structure and dynamics are realistically modeled in our simulations.

\section{Structural variation of the simulated systems}

To analyze the dynamic variation, we computed the RMSD (measured in $\mathrm{nm}$ ) relative to the starting structure, along with the radius of gyration $\left(\mathrm{R}_{\mathrm{g}}, \mathrm{nm}\right)$ and solvent-accessible surface area $\left(\mathrm{SASA}, \mathrm{nm}^{2}\right.$ ) for all the 12 PS1 and 12 PS2 systems. The average and standard deviation of RMSD and $\mathrm{R}_{\mathrm{g}}$ are shown in Fig. 2 and SASA in Fig. S4, and their time-dependent plots are represented in Fig. S5. The large variations reflect the use of three very distinct starting conformations, as desired to evaluate the impact of conformation states on calcium binding. Several locally stable conformations were visited repeatedly. In some simulations, the RMSD, $\mathrm{R}_{\mathrm{g}}$ and SASA diverged during the last part of the $1 \mu$ s run (Fig. S5), reflecting the non-ergodicity of the full conformation space for proteins with large loop motions (ns to $\mu$ s timescale) ${ }^{87}$ Hence, our emphasis was only on the non-equilibrium calcium binding and transfer between sites, rather than equilibrated binding affinities. Despite the variations, we note that the RMSD values of PS1 were higher than PS2 due to the larger size of PS1 (the longer HL2 loop). In general, structural variations (RMSD) were larger for conformer 2, as also supported by the $\mathrm{R}_{\mathrm{g}}$ and SASA being higher for PS1 than PS2 and for conformer 2 in general (Fig. 2, S4 and S5). Thus, the variations from stable trajectories are specific to some systems and largely reflect the slow motions of HL2 (a RMSD plot for HL2 is shown in Fig. S6 with averages and standard deviations shown in Fig. 3), as discussed further below. 
(a) PS1
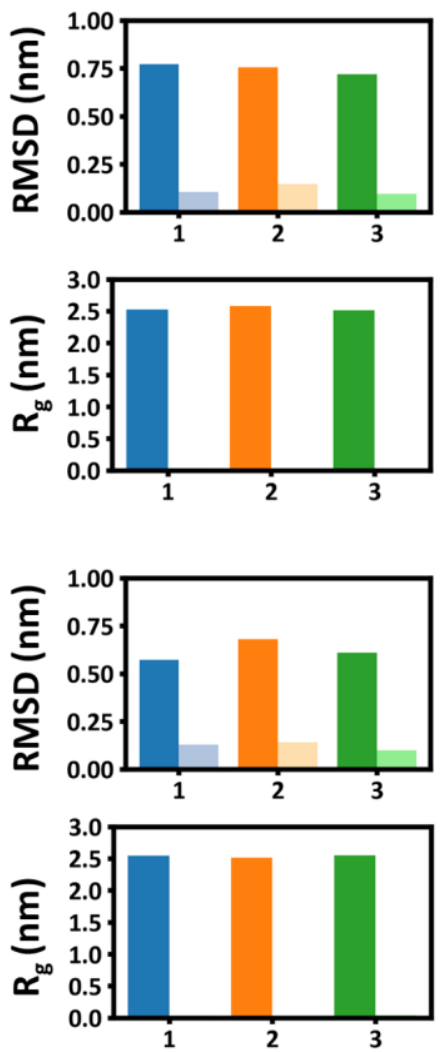

(b) PS1 D257-H $\mathrm{Ca}^{2+}$ placed near D385 in PS1 and D366 in PS2
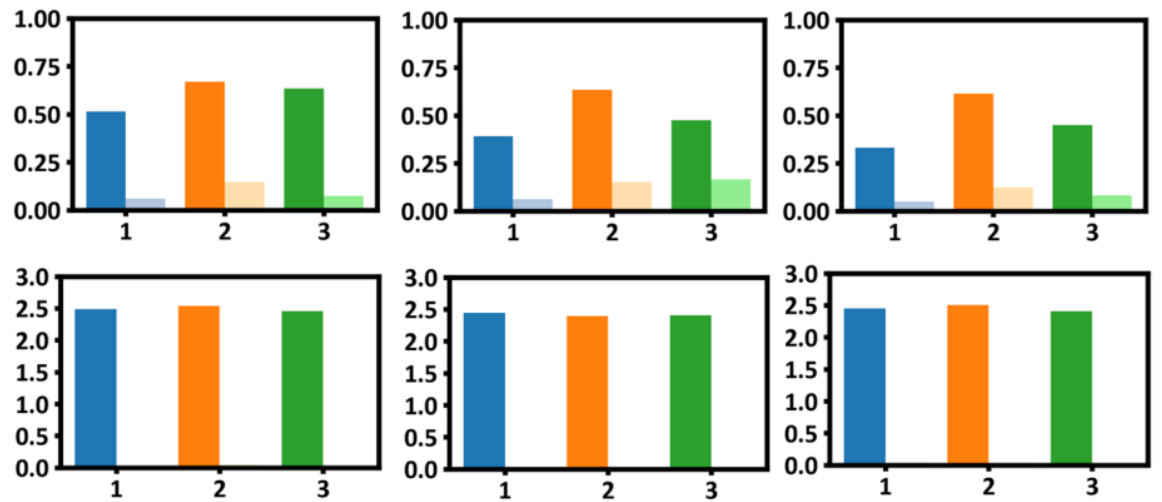

$\mathrm{Ca}^{2+}$ placed on HL2 loop
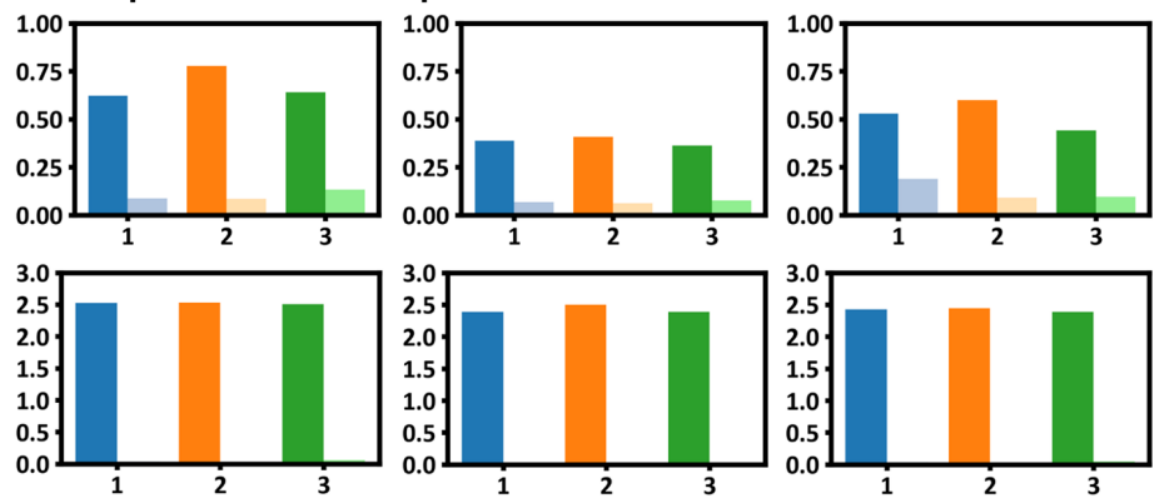

Fig. 2 Averages and standard deviations of RMSD and $\mathbf{R}_{\mathrm{g}}$ during the simulations. (a) PS1 with both catalytic D257 and D385 charged. (b) PS1 D257-H (D257 protonated). (c) PS2 with both catalytic D263 and D366 charged. (d) PS2 D263-H (D263 protonated). Dark blue, orange and green represent the averages and their corresponding light colors represent the standard deviations for the three independent simulations of each PS state. Blue and orange represent compact conformations and green is an open conformation. 
(a) PS1
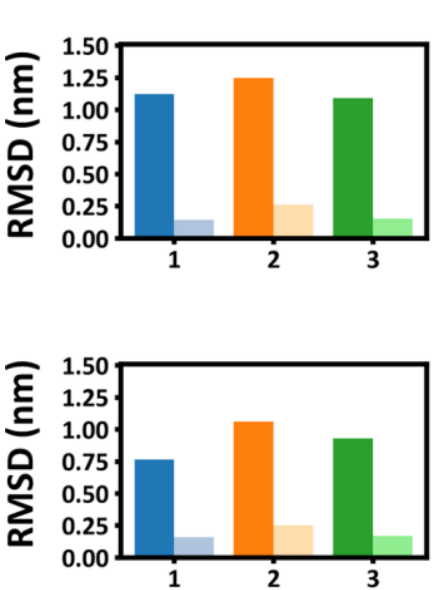

(b) PS1 D257-H

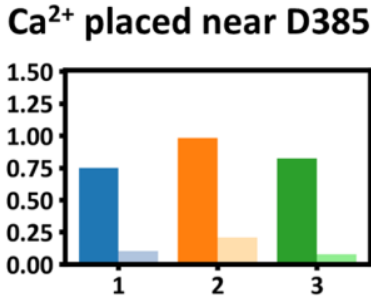

$\mathrm{Ca}^{2+}$ placed on HL2 loop

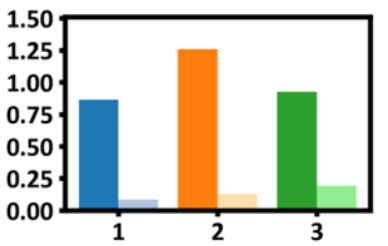

(d) PS2 D263-H

(c) PS2
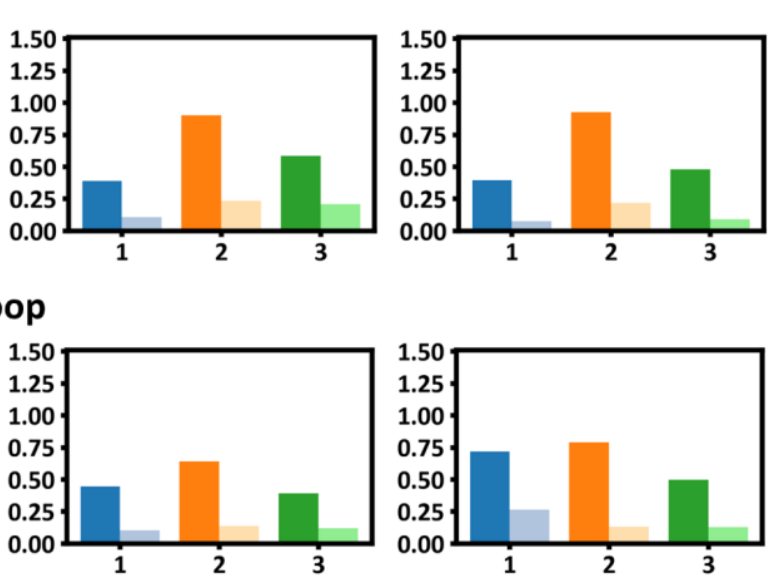

Fig. 3 Averages and standard deviations of RMSD of the HL2 loop during the simulations. (a) PS1 with both catalytic D257 and D385 charged. (b) PS1 D257-H (D257 protonated). (c) PS2 with both catalytic D263 and D366 charged. (d) PS2 D263-H (D263 protonated).

(a) PS1

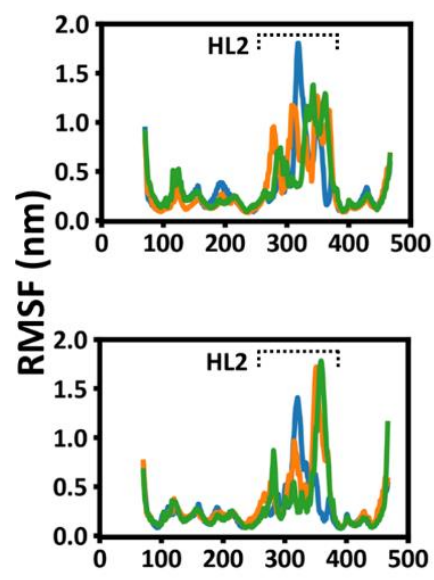

(b) PS1 D257-H

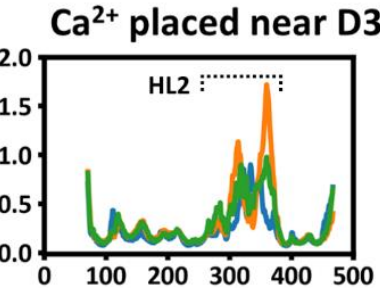

(c) PS2

85 in PS1 and D366 in PS2

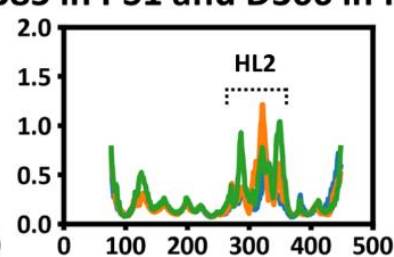

(d) PS2 D263-H

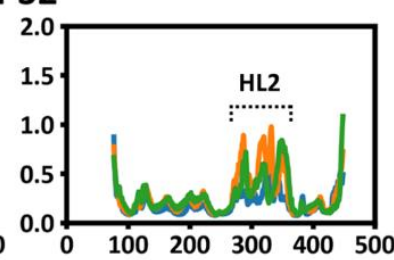

$\mathrm{Ca}^{2+}$ placed on HL2 loop
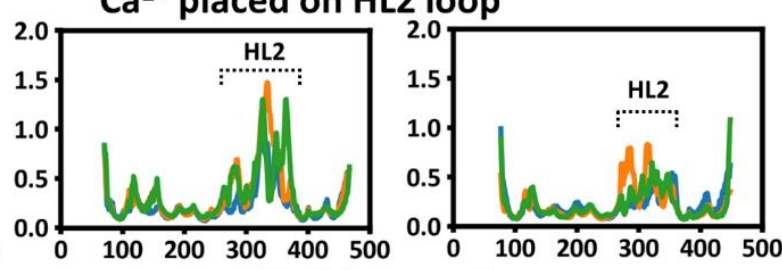

Residue number

Fig. 4 RMSF plots of the presenilin residues in each simulation. (a) PS1 (with both catalytic D257 and D385 charged). (b) PS1 D257-H (with D257 protonated). (c) PS2 (with both catalytic D263 and D366 charged). (d) PS2 D263-H (with D263 protonated).

Fig. 3 (and Fig. S6) shows the RMSD of HL2 loop and Fig. 4 shows the root mean-squared fluctuations (RMSF) of presenilin residues for each simulation. The average RMSD of the HL2 loop for the seed 2 (orange, Fig. 3) was larger than the other two conformers. The very large fluctuations of the residues of HL2 between TM6 and TM7 were also confirmed by the RMSF plots (Fig. 4). As expected, the fluctuations were higher for PS1 with the much larger loop. 
Furthermore, PS1 (with both catalytic aspartates charged, Fig. 4a) displayed more loop motion than PS1 D257-H (Fig. 4b); a similar trend was not observed for PS2 (Fig. 4c-4d).

We studied the collective motions of calcium-associated PS1 and PS2 with and without protonation using PCA, as summarized in Fig. 5, Figs. S7-S8 for the last 500 ns (Fig. S9 shows the first $500 \mathrm{~ns}$ ). The most important eigenvectors (EV) are shown for all three simulations of each of the eight systems (four with $\mathrm{Ca}^{2+}$ placed near D385/D366 and four with $\mathrm{Ca}^{2+}$ placed on HL2 loop). The PS1 simulations (Fig. 5a) represent more entropic states than PS2, again because of the larger HL2. The eigenvalues of the essential eigenvectors that define the magnitude of the protein motions were also clearly larger in PS1 regardless of protonation state (Fig. 5a-5b). The PS2 ensemble without aspartate protonation (Fig. 5c) is also similar to the ensemble with charged aspartate (Fig. 5d); we thus conclude that presenilin is a multistate protein, whose major conformational differences are controlled by the HL2 loop, and these ensembles are not affected by the protonation inside the membrane, as expected.

For the twelve independent simulations of PS1 and PS2 where $\mathrm{Ca}^{2+}$ was initially placed within the HL2 loop (Fig. 5, bottom) similar multistate ensembles caused by HL2 were observed, but we saw consistently more restricted conformational states in simulations where both aspartates were charged (as also seen from Fig. 3a, 3c and Fig. S6a, S6c), i.e. calcium dampens HL2 motions considerably. This tendency was seen for six simulations, comparing the upper and lower pairs of systems in Fig. 5a and c, and we thus consider this finding significant. However, for the systems where one aspartate was protonated (Asp257 in PS1 and Asp263 in PS2), this trend was missing. The initial $500 \mathrm{~ns}$ simulations also showed a comparable behavior with high-entropy states as summarized in Fig. S9.

\section{Calcium binding and transfer events}

The three independent simulations of each PS1 and PS2 protonation state represent two compact conformations (blue and orange) and one distinctly open conformation (green), which have been argued to reflect the two states that produce short and long $A \beta$ peptides in $\gamma$-secretase. ${ }^{64,72}$ In the two PS1 compact conformations where $\mathrm{Ca}^{2+}$ was initially placed near the catalytic aspartate on TM7, $\mathrm{Ca}^{2+}$ remained in the same place throughout all $1 \mu$ s of simulation (Fig. S10a-S10b, first row). In PS2 conformer 1 (with both Asp charged, compact conformation, Fig. S10c, first row, blue), we observed a single, highly characteristic $\mathrm{Ca}^{2+}$ movement to the TM6-TM7 loop and back to the catalytic Asp. Due to the strong negative charge of the catalytic aspartates, $\mathrm{Ca}^{2+}$ moves back from loop to the catalytic site. 
(a) PS1

2

$\begin{array}{ll}\text { (b) PS1 D257-H } & \text { (c) PS2 }\end{array}$

500-1000 ns

$\mathrm{Ca}^{2+}$ placed near D385 in PS1 and D366 in PS2
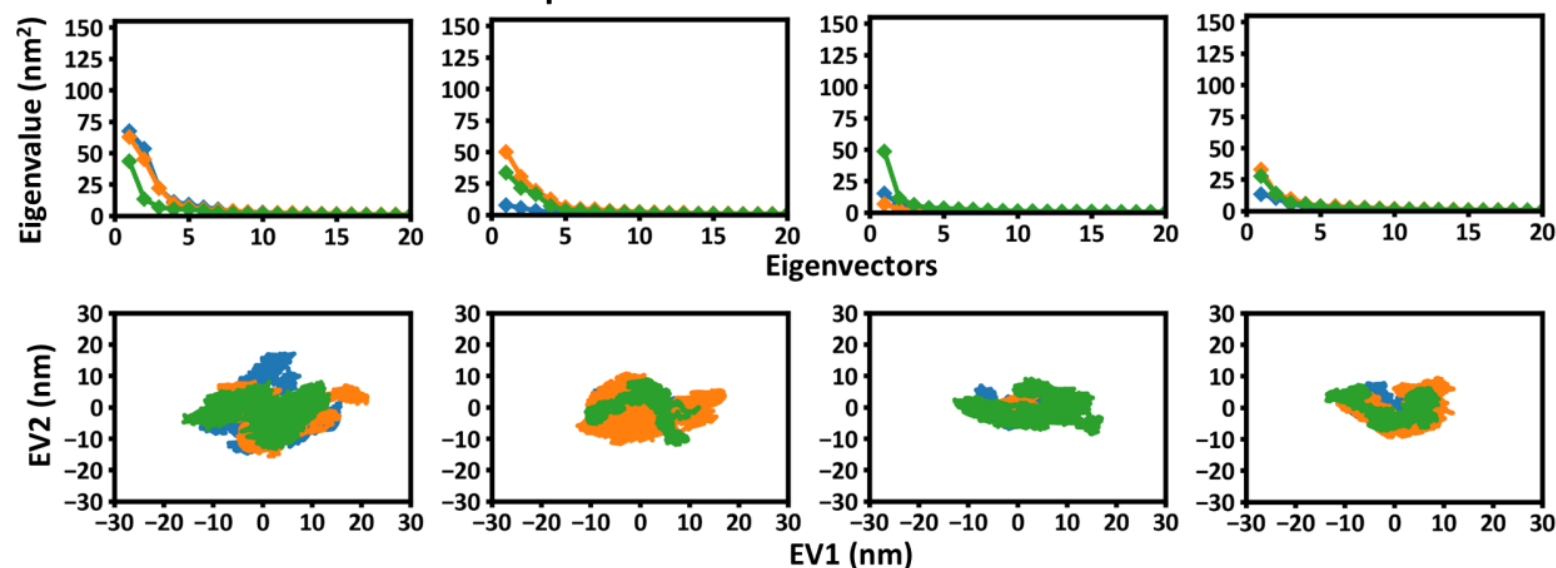

$\mathrm{Ca}^{2+}$ placed on HL2 loop
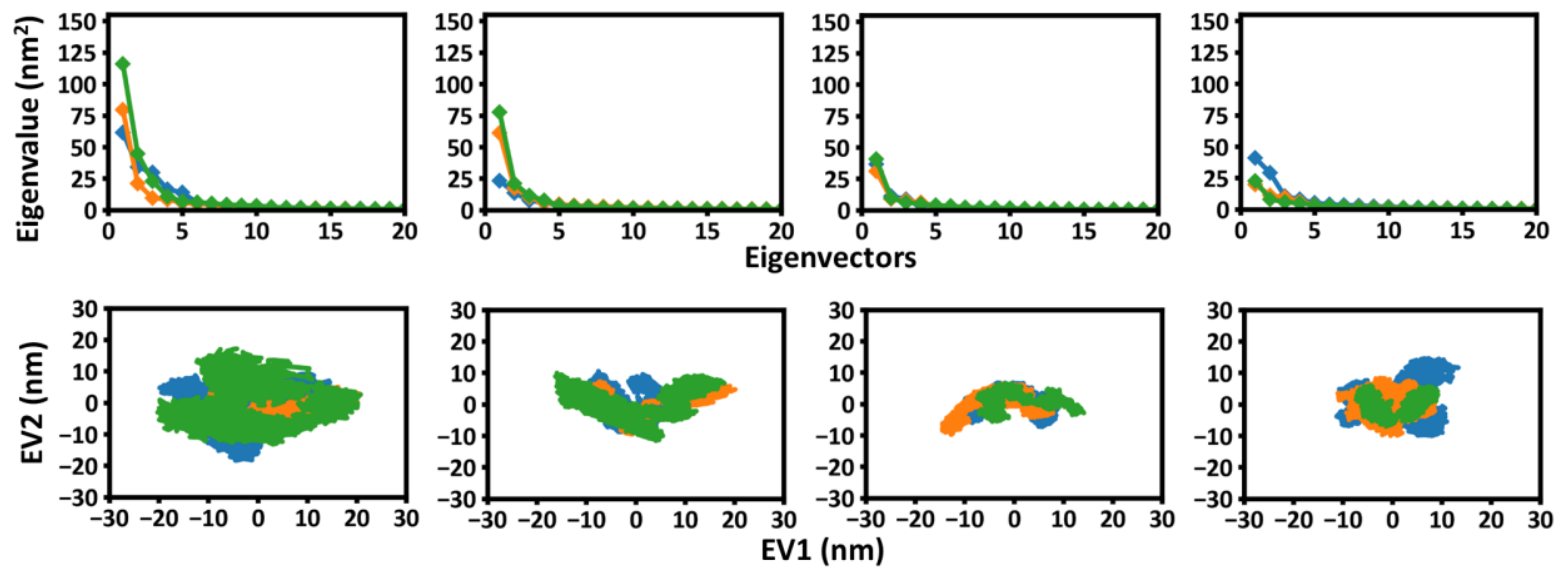

Fig. 5 Plots of eigenvectors versus eigenvalues and eigenvector 1 versus 2 for the equilibrated simulations (500-1000 ns). (a) PS1 (with both catalytic D257 and D385 charged). (b) PS1 D257H (with D257 protonated). (c) PS2 (with both catalytic D263 and D366 charged). (d) PS2 D263H (with D263 protonated).

In both compact conformations of PS2 with Asp263 protonated (Fig. S10d, first row, orange), $\mathrm{Ca}^{2+}$ moved to the loop and remained there. In conformer 1 , the movement occurred during the equilibrated final $500 \mathrm{~ns}$ and in the conformer $2, \mathrm{Ca}^{2+}$ moved at the beginning of the simulation. The absence of return events could suggest that the compact PS2 state opens slightly in the equilibrated phase to allow the $\mathrm{Ca}^{2+}$ movement to the loop, but that the loss of negative charge due to protonation prevents $\mathrm{Ca}^{2+}$ from entering the catalytic site again. If this interpretation is correct, it could suggest that low $\mathrm{pH}$ prevents calcium binding to the catalytic site. This structural mechanism could be the basis of presenilin-controlled calcium transport to the lysosome, which is probably required for lysosome proteolysis, if two important observations, the requirement of calcium and presenilin for the lysosome, are combined. ${ }^{88,89}$ 
The green trajectories represent the open conformations, where $\mathrm{Ca}^{2+}$ moved away towards the cytosolic side. Importantly, we found that the $\mathrm{Ca}^{2+}$ movement followed a specific path, i.e. from catalytic Asp to the TM6-TM7 loop and then back and forth from loop to cytosol or back to the catalytic Asp. The $\mathrm{Ca}^{2+}$ movement events are summarized in Table S3. Except PS1 with protonated Asp257, $\mathrm{Ca}^{2+}$ moved to the loop, then several times back and forth from loop to cytosol. However, typically one incident of $\mathrm{Ca}^{2+}$ movement to the catalytic Asp was observed in both PS1 protonation states and in one PS2 state with both Asp charged. The PS1 with protonated Asp257 (Fig. S10b, first row, green line) features an interesting movement back and forth from catalytic Asp to loop. We consider this movement potentially important for two functions of presenilin, namely autoproteolysis and maturation on one hand and calcium transport on the other. The movement between the catalytic site and HL2, which is both a maturation loop and a calcium recognition loop, suggests the possibility that the two functions could be directly related, although the simulations offer no evidence of this possibility. Apart from this, interactions between calcium and TM9 were consistently observed, but only in the open conformation of PS1.

Fig. S11 summarizes the most important movements to and away from the primary carboxylic residues of the calcium binding sites. In conformer 1 (compact conformation) where $\mathrm{Ca}^{2+}$ was placed towards the cytosol on the TM6-TM7 loop residues (Fig. S10 bottom), the proteins with protonated aspartate (Fig. S11b and S11d, blue color) displayed more stable positioning of $\mathrm{Ca}^{2+}$ compared to PS with both aspartates charged (Fig. S11a and S11c, blue color). The consistent oscillations seen in both Figs. S10 and S11 show that we effectively sample movements of calcium to and from the sites, making these events significant by their recurrent observation.

In conformers 2 (compact) and 3 (open conformation), the back and forth movement of $\mathrm{Ca}^{2+}$ from loop to cytosol was a common event (Fig. S10 lower row, Fig. S11 orange and green lines). The changes in distances seen in Fig. 5 for the compact conformation of PS2 (conformer 2 with both charged aspartates) again reflects the movement of calcium from HL2 to the catalytic aspartate during the end of simulation. Another prominent event is the interaction with the terminal residues of TM9, which has been reported to play a role in $\mathrm{Ca}^{2+}$ transport. $^{42}$ 

(a) PS1
(b) PS1 D257-H
(c) PS2
(d) PS2 D263-H

$\mathrm{Ca}^{2+}$ placed near D385 in PS1 and D366 in PS2

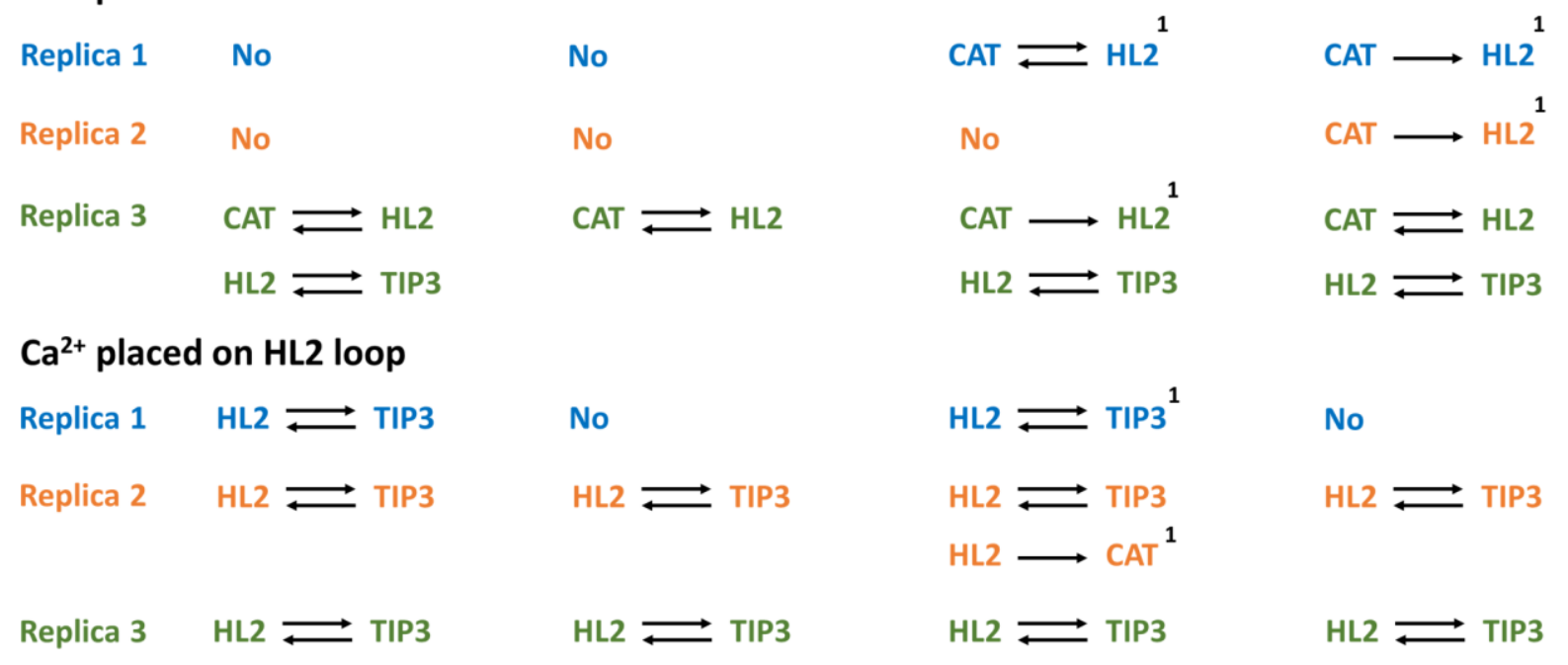

Fig. 6 Summary of notable events of $\mathbf{C a}^{2+}$ movement. CAT represent the catalytic site surrounded by the catalytic aspartates, HL2 is the hydrophilic loop 2 between TM6 and TM7, TIP3 is the TIP3P water molecules. Blue, orange and green colors represent the three conformers. The superscript ${ }^{1}$ represents the one-time event, whereas all other events occurred multiple times. (a) PS1 (with both catalytic D257 and D385 charged). (b) PS1 D257-H (with D257 protonated). (c) PS2 (with both catalytic D263 and D366 charged). (d) PS2 D263-H (with D263 protonated).

\section{Summarizing the major calcium sites within presenilin}

Fig. 6 summarizes the main calcium movement events identified in this work, together with the important pathways of calcium movement between locations, based on analysis of the plots in Figs. 7, 8 and Figs. S10, S11 and supporting information. The events are supported by indirect experimental data. Most notably, PS1 mutagenesis indicates that TM7 and TM9 play a key role in $\mathrm{Ca}^{2+}$ regulation, largely supporting our assignment of calcium binding states. ${ }^{42}$ In addition, the TM9 segment is highly flexible and water-accessible with residues surrounding the PALP motif, which lies close to the catalytic aspartates ${ }^{90}$ and undergoes conformational changes to activate the catalytic site of presenilin..$^{91}$ 
(a) PS1

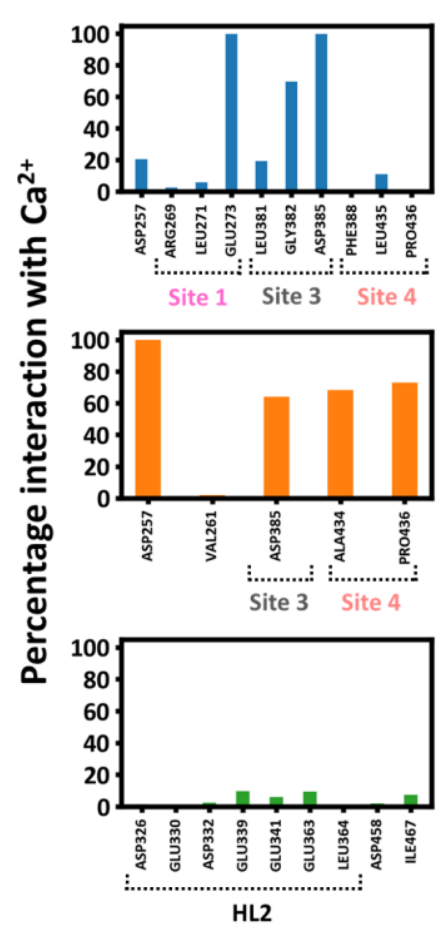

(b) PS1 D257-H
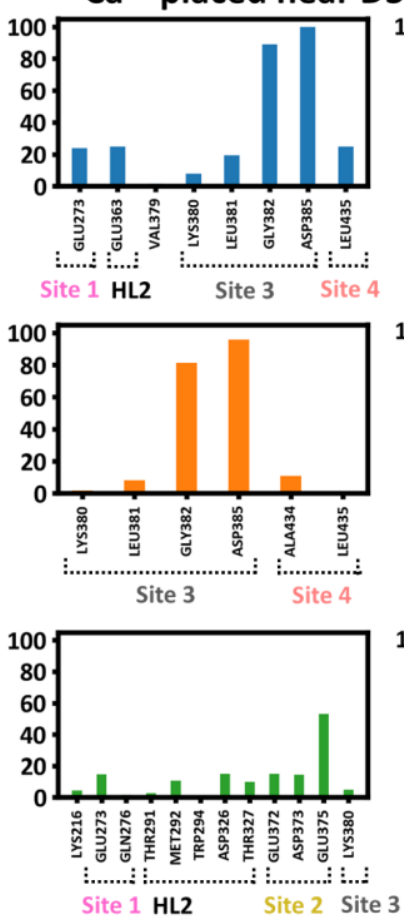

(c) PS2

(d) PS2 D263-H

Fig. $7 \mathrm{Ca}^{2+}$ interactions with residues of $>1 \%$ persistence during the final $500 \mathrm{~ns}$ in systems where $\mathrm{Ca}^{2+}$ was placed in the catalytic site. (a) PS1 (with both catalytic D257 and D385 charged). (b) PS1 D257-H (with D257 protonated). (c) PS2 (with both catalytic D263 and D366 charged). (d) PS2 D263-H (with D263 protonated).

The main calcium-binding sites obtained in our study are shown in Figs. 7, 8 and 9, based on interaction analysis over the simulated trajectories as elaborated in Figs. S12-S14, using a distance threshold of $4 \AA$ when counting interactions. $\mathrm{Ca}^{2+}$ mainly interacted with glutamates and aspartates. In simulations where the catalytic aspartate of TM6 was protonated, $\mathrm{Ca}^{2+}$ mainly interacted with the other charged Asp385/366. When both aspartates were charged, $\mathrm{Ca}^{2+}$ interacted with both. $\mathrm{Ca}^{2+}$ did not interaction significantly with other TM6 residues. Previous studies have suggested that TM6 residues of PS1 are not the main contributors to $\mathrm{Ca}^{2+}$ effects (directly by transport or indirectly by regulation of other calcium transport proteins), except for a few residues, i.e. T245, S254 and A260. ${ }^{42}$ T245 is solvent-exposed towards the N-terminal of TM6, whereas S254 is buried and A260 is solvent-accessible towards the C-terminal. $\mathrm{Ca}^{2+}$ did not interact with any of these residues in our simulations. Based on our diverse structural starting points and trajectories, we argue against a role of TM6 except via interaction with the catalytic aspartate. 
(a) PS1

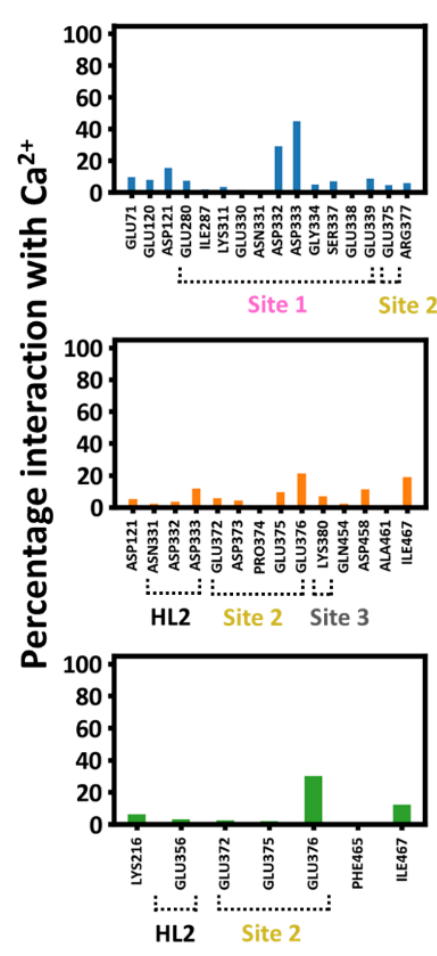

(b) PS1 D257-H

$\mathrm{Ca}^{2+}$ placed on $\mathrm{HL2}$ loop
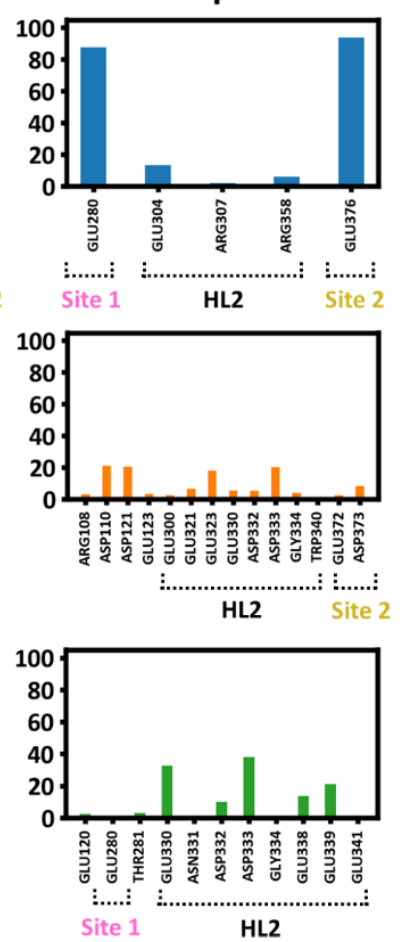

(c) PS2
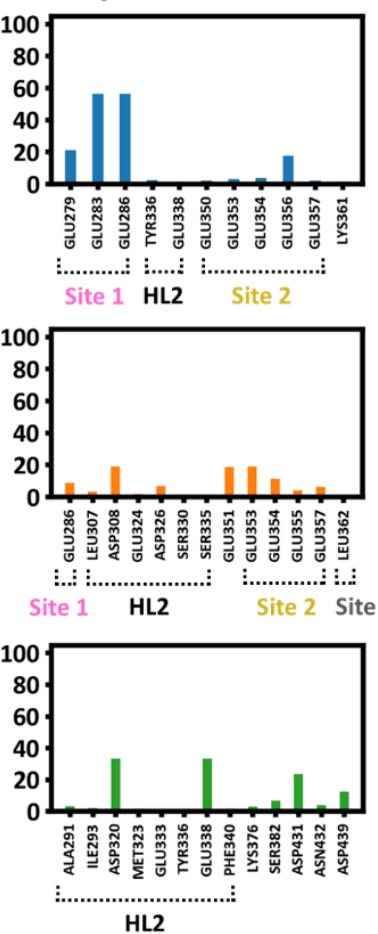

(d) PS2 D263-H

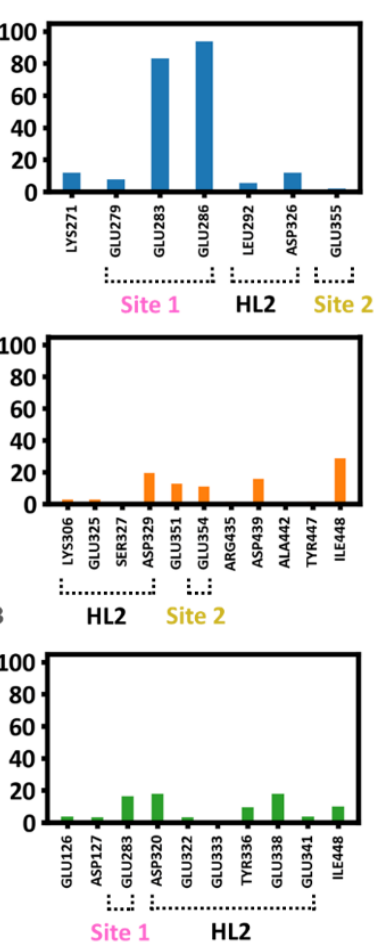

Fig. $8 \mathrm{Ca}^{2+}$ interactions with $>1 \%$ prevalence during the final $500 \mathrm{~ns}$ in systems where $\mathrm{Ca}^{2+}$ was placed on HL2. (a) PS1 (with both catalytic D257 and D385 charged). (b) PS1 D257-H (with D257 protonated). (c) PS2 (with both catalytic D263 and D366 charged). (d) PS2 D263-H (with D263 protonated).

More importantly, we identified consistent $\mathrm{Ca}^{2+}$ interactions with HL2 towards the cytosol (site 1 in Fig. 9), notably R269/275, L271/277, E273/279 and E280/286 in PS1/PS2. We note that the fAD-linked PS1 mutant E273A has been reported to impair $\mathrm{Ca}^{2+}$ transport function, ${ }^{43}$ which supports our identification of a calcium site in this part of presenilin. However, we did not observe any complete transfer events, not even in the open conformation, and in none of the protonation states, yet the binding sites could imply a calcium recognition function of HL2. E273 on HL2 of PS1 formed prominent and persistent interactions with $\mathrm{Ca}^{2+}$ (up to $90 \%$ of the simulation time). We also saw persistent interaction with E279 in PS2 (20\% prevalence), E280 in PS1 and E286 in PS2 (90\%), and E283 in PS2 (80\%). Experimental support for a role of HL2 comes from mutational deletion of HL2 (Asp302-Glu372 from PS1) inhibiting ER Ca ${ }^{2+}$ transport, whereas partial loop removal (exon 8: PS1- $\triangle \mathrm{E} 8$ and exon 9: PS1- $\triangle \mathrm{E} 9$ mutants) does not. ${ }^{41,92}$

A poly-glutamate stretch EELEEEEE (residues 350-357) exists close to TM7 of PS2 (site 2 in Fig. 9). We observed that $\mathrm{Ca}^{2+}$ also bound consistently to this region during our simulations. This long stretch is absent in PS1; however, several glutamates are present in the corresponding region of PS1. During our simulations, E372/353, D373/E354, E375/356 and E376/357 interacted 
with calcium in PS1/PS2. The PS1 residue E376 at the start of the TM7 segment is solvent accessible and $\mathrm{Ca}^{2+}$ transport is impaired if this residue is mutated. ${ }^{42}$ We found that this residue interacted with $\mathrm{Ca}^{2+}$ up to $90 \%$ of the simulation time. The corresponding interaction with E357 was however not observed in PS2. Instead, PS2 interacted with $\mathrm{Ca}^{2+}$ via other residues of the polyglutamate stretch, i.e. E350, E351 and E355 near the beginning of TM7.

We also observed specific interactions with residues of TM7 and TM9. The TM7 residues towards the $\mathrm{N}$-terminal are highly water accessible and many of them interacted with $\mathrm{Ca}^{2+}$ : The TM7 region V379-F388 in PS1 and V360-D366 in PS2 interacted consistently with $\mathrm{Ca}^{2+}$, as did K380/361, L381/362, G382/363 and the catalytic Asp385/366 in PS1/PS2 (site 3 in Fig. 9). Interestingly, it has been reported that cysteine mutation of five residues in this region of PS1 (G382, G384, D385, I387 and Y389) abrogate the $\mathrm{Ca}^{2+}$ leak function..$^{42} \mathrm{D} 385 \mathrm{~A}$ mutation has also been reported to cause loss of $\mathrm{Ca}^{2+}$ leak function. ${ }^{93}$ Our observations thus support the reported hotspots by Nelson et $\mathrm{a}^{42}$ but since we see no evidence for actual leak events, we instead propose that these sites are calcium sensing sites that modify HL2-governed regulation of other calcium transport proteins to produce the observed leak effect. However, transfer could possibly require enhanced sampling if larger loop or helix motions are involved.

Many TM9 residues from either side of the membrane interacted with $\mathrm{Ca}^{2+}$. These two sides of TM9 formed highly water accessible cavities, which were also easily accessible by $\mathrm{Ca}^{2+}$. The PALP motif (433-436 in PS1 and 414-417 in PS2) on TM9 (accessible from cytosol) is highly conserved and lies near the catalytic aspartates (site 4 in Fig. 9). The PS1 mutation P433A/L abrogates catalytic activity of $\gamma$-secretase and has been reported to possibly keep presenilin in a more open conformation, ${ }^{91,94}$ consistent with the FIST model. ${ }^{38,72}$ Cysteine mutation of P433 and A434 in PS1 did not affect $\mathrm{Ca}^{2+}$ leak. ${ }^{42}$ In contrast, cysteine mutations of L435 and P436 have been reported to cause loss of $\mathrm{Ca}^{2+}$ leak. ${ }^{42}$ Our data thus suggest that the PALP motif interacts with $\mathrm{Ca}^{2+} . \mathrm{Ca}^{2+}$ interacted with this motif in six of 12 presenilin simulations (where $\mathrm{Ca}^{2+}$ was placed near the catalytic aspartates), which indicates that the PALP motif plays a role in $\mathrm{Ca}^{2+}$ recognition, if not actual transport as previously suggested. ${ }^{42}$

Six PS1 mutations in middle of TM9 have been reported to inhibit $\mathrm{Ca}^{2+}$ leak activity. ${ }^{42} \mathrm{Ca}^{2+}$ did not interact with any of these residues, mainly due to the buried position of most of these residues in presenilin. The middle to C-terminal part of TM9, which is highly solvent accessible interacted with $\mathrm{Ca}^{2+}$. These residues include Q454/R435, D458/439, A461/442 and I467/448 in PS1/PS2. In PS2, additional interactions were observed between $\mathrm{Ca}^{2+}$ and Y447, D431 and N432. The interactions of TM9 with $\mathrm{Ca}^{2+}$ are in line with a literature report suggesting that most TM9 mutations abolish ER $\mathrm{Ca}^{2+}$ transport. ${ }^{42}$ 
We further analyzed the relative binding affinities when $\mathrm{Ca}^{2+}$ was placed near the catalytic aspartates, using MMGBSA (Fig. S15). ${ }^{95}$ The absolute affinities are not meaningful as the are very force-field dependent, but the conformation-state effects on affinity can be estimated. The Coulomb energies dominates the binding energy: In PS1 when both the catalytic aspartates were deprotonated, the Coulomb binding energies were as expected more negative (Fig. S15a) than when Asp257 was protonated (Fig. S15b). The interacting residues are summarized in Fig. 9c and 9d. $\mathrm{Ca}^{2+}$ interacted with two charges residues (Asp/Glu, Fig. 9c). In two simulations of PS1 with D257 protonated, $\mathrm{Ca}^{2+}$ interacted with only one charged residue Asp385 and in the third simulation with two charged residues (Fig. 9d). In simulations 1 and 2 of PS1, $\mathrm{Ca}^{2+}$ was present in the catalytic site and in simulation 3 the $\mathrm{Ca}^{2+}$ was present in HL2/site 2, making simulation 3 not directly comparable. However, for PS2, no clear effect of protonation was seen (Fig. S15c-d). In all these systems, $\mathrm{Ca}^{2+}$ interacted with two charged residues (Fig. 9e-9f). $\mathrm{Ca}^{2+}$ was present in the catalytic site (Site 3) only in the deprotonated state (Fig. 9e) but in HL2 or site 2 in all other systems.

In order to further understand the effect of protein conformations on $\mathrm{pK}_{\mathrm{a}}$, the 24 representative structures of PS1 and PS2 were analyzed (Table S4). 12 of these structures had both catalytic aspartates negatively charged and 12 had one protonated aspartate (D257/D263 in PS1/PS2). The average $\mathrm{pK}_{\mathrm{a}}$ values of the initial PS2 conformations were 4.8 and 4.9 for D263 and D366, respectively (Table S1) with both aspartates in charged state. In the simulated structures where $\mathrm{Ca}^{2+}$ was initially placed in the catalytic site, the average $\mathrm{pK}_{\mathrm{a}}$ were 5.3 and 6.5 for D263 and D366 (Table S4). These $\mathrm{pK}_{\mathrm{a}}$ values were higher than the initial conformations, suggesting that the $\mathrm{pK}_{\mathrm{a}}$ partly depends on the protein conformations and local environment. Both residues were charged at pH 6-8 and only at pH 5, D366 became neutral (Table S4, states 7-9). The difference in $\mathrm{pK}_{\mathrm{a}}$ might be attributed to $\mathrm{Ca}^{2+}$, as implied by the simulated structures with $\mathrm{Ca}^{2+}$ initially on $\mathrm{HL} 2$. In this case, average $\mathrm{pK}_{\mathrm{a}}$ values resembled those of the initial PS2 conformations (4.6 and 4.9 for D263 and D366, Table S4, states 19-21). The PROPKA program does not account well for metal ions, potentially affecting the $\mathrm{pK}_{\mathrm{a}}$ calculation when $\mathrm{Ca}^{2+}$ resides near the catalytic aspartates. ${ }^{96}$ The comparison of the initial PS2 conformations with the representative structures (deprotonated states) is shown in Fig. S16. We also analyzed PS2 states where one aspartate was already protonated. In PS2 D263-H (D263 protonated), Asp263 preferred to be protonated at pH $\leq 6$ (Table S4, states 10-12 and 22-24). This supports our choice of Asp263 as the protonation site if the active site is protonated at all. Similarly, in PS1, both the catalytic aspartates were charged at pH 7-8 (Table S4, states 1-6 and 13-18), except for one (Table S4, state 16) where Asp257 showed a strong propensity to be protonated. At $\mathrm{pH} 6$ or below, Asp257 showed the highest tendency to be protonated, with only three cases where Asp385 also could be protonated, again supporting Asp257/Asp263 as the primary protonation site. 
(a) $\mathrm{Ca}^{2+}$ sites in presenilin

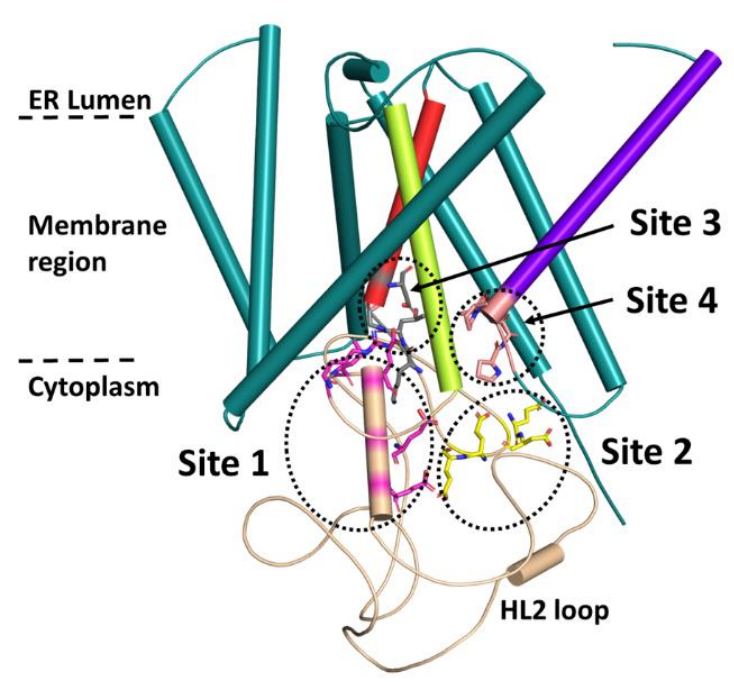

(c) PS1

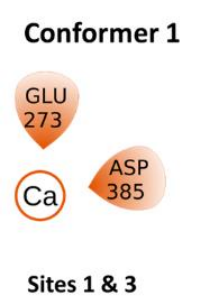

(e) PS2

\begin{abstract}
Conformer 1
\end{abstract}

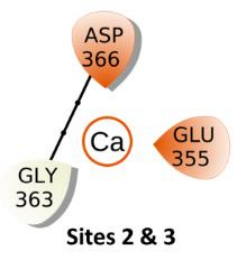

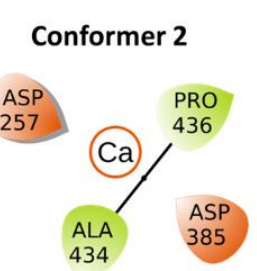

Sites 3 \& 4

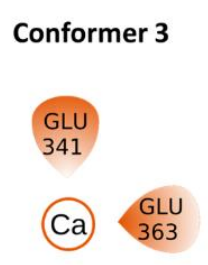

HL2 loop (b) Residues forming $\mathrm{Ca}^{2+}$ sites

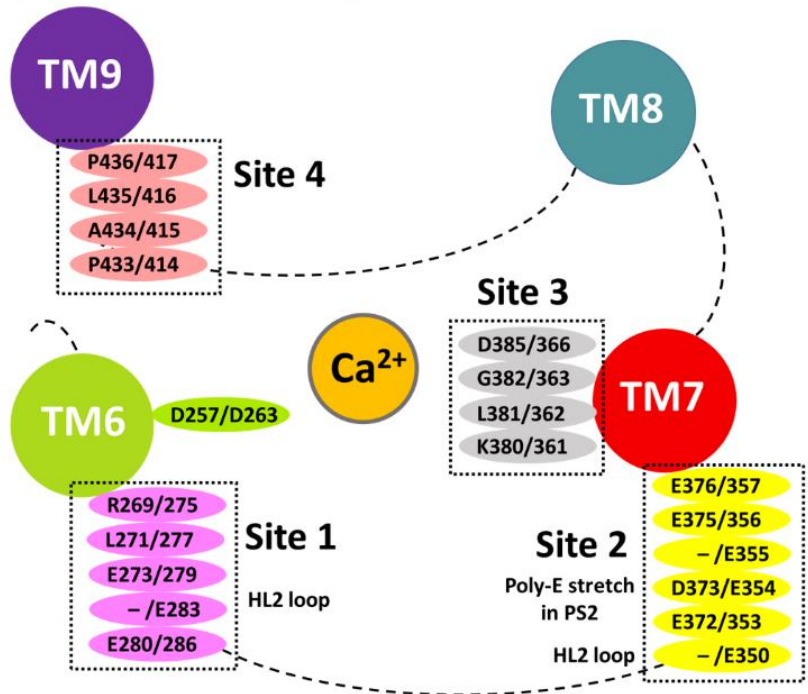

(d) PS1 D257-H

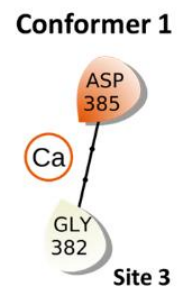

Conformer 2

Conformer 3
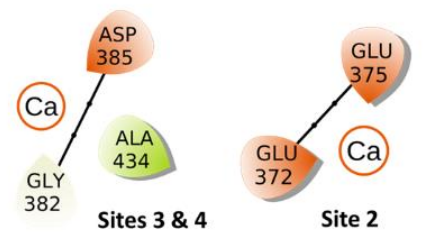

(f) PS2 D263-H

Conformer 1

Conformer 2

Conformer 3

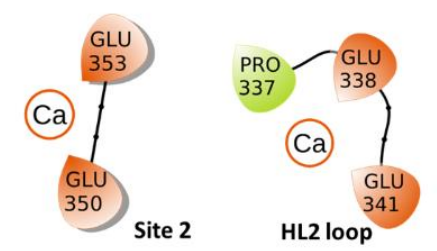

Fig. 9 Four calcium binding sites identified in this work, shown on the background structure of conformer 1 of PS1. (a) Total overview of the identified sites. Site 1 (magenta) comprises HL2 (wheat) next to TM6 (towards the C-terminal). Site 2 (yellow) is formed by the poly-glutamate stretch in PS2 and its homologous residues in PS1 within HL2 immediate before TM7 (towards the N-terminal). Site 3 (grey) is the catalytic site of TM7, and site 4 (peach) involves PALP on TM9. (b) Specific residues involved in PS1 and PS2 are represented as "PS1 residue/PS2 residue". (c-f) The $\mathrm{Ca}^{2+}$ interactions of the representative structure of the final $500 \mathrm{~ns}$ (where $\mathrm{Ca}^{2+}$ was initially placed near the catalytic aspartates). In the trajectories where $\mathrm{Ca}^{2+}$ was placed on the HL2 loop, the results are more complex, as described in the text, Fig. 8 and Table S3. 


\section{Biological implications: Presenilin regulation of $\left[\mathrm{Ca}^{2+}\right]$}

$\mathrm{Ca}^{2+}$ transport by presenilins via an assumed conductance pore has been proposed to occur in the immature form when associated with the ER ${ }^{41}$. The PS1 pore is supposedly formed by TM7 and TM9, with no major role of TM6. ${ }^{41,42}$ The hydrophilic catalytic cavity may also contribute to calcium binding, ${ }^{41}$ and it is notable that two aspartates of the interior pore of some transmembrane helix calcium transporters are $\mathrm{pH}$-dependent calcium binding sites. The residues surrounding the PAL motif and the N- and C-terminal regions of TM9 are highly water accessible and close to the catalytic aspartates. ${ }^{76}$ The conformational changes around this region are important for activating the catalytic site..$^{91}$ These various sites are therefore the likely hotspots for calcium interaction.

Our structural dynamics suggest that calcium sites change the dynamics, dampen HL2 motions, and affect TM7 and TM9. When the catalytic site is protonated, calcium is lost to the HL2. These findings open for a plausible model of $\mathrm{pH}$-dependent calcium regulatory function of presenilin, with low $\mathrm{pH}$ and calcium binding preventing autoproteolysis due to calcium blockage. In contrast, the logical inference is that if calcium is not available, HL2 will be cleaved and cause presenilin to mature, possibly in the context of the $\gamma$-secretase complex. Although a hypothesis, this view gains support from a recent study of an exon 9 deletion and D257A mutant, having lost three of the main calcium sites that we identified, which accumulates separately from the $\gamma$ secretase complex and leads to increased calcium entry to ER probably via other calcium transport proteins, such as the ryanodine receptor. ${ }^{97}$

A recent paper ${ }^{98}$ stated that, despite the major importance of calcium homeostasis to lysosome dysfunction and storage diseases, the ER calcium refill mechanism remains unknown; they found that ER is somehow the direct source of the calcium. We have previously suggested that APP/A $\beta$ regulates $\mathrm{Cu} / \mathrm{Zn}$ and $\mathrm{Zn} / \mathrm{Ca}$ ratios by divalent metal transport, ${ }^{99,100}$ and knockdown of APP may increase ER calcium levels. ${ }^{101}$ Considering the importance of tight regulation of these ions, one could imagine that presenilin plays two parts: One in immature form as a calcium sensor regulating calcium transport to the lysosome, ER, and mitochondria, and another as matured catalytic subunit of the most important membrane protease. Evidence for presenilin-mediated crosstalk between lysosome, ER, and mitochondria is rapidly emerging. ${ }^{50,102-104}$ The fact that open, less stable conformations of PS tend to be favored by pathogenic mutations ${ }^{38}$ could affect both of these roles. Accordingly, we expect mutations that increase calcium leak to also increase the $A \beta_{42} / A \beta_{40}$ ratio. Interaction of presenilin with Bax inhibitor 1, which regulates apoptosis, ${ }^{105}$ probably plays a central role in balancing these functions. ${ }^{106}$

We note that presenilin is perhaps also involved in mitochondrial quality control, which features centrally in $\mathrm{AD}^{103,107-110}$ and whose impairment may explain proteopathy via accumulating energy inefficiencies that lead to impairment of ATP-costly protein turnover. ${ }^{15}$ ER- 
mitochondria-associated membranes are notoriously enriched with presenilin that regulates $\mathrm{Ca}^{2+}$ transfer between the two organelles. ${ }^{111}$ Recent work suggests that presenilins control ER $\mathrm{Ca}^{2+}$ leak to mitochondria in $\beta$-cells, thereby increasing mitochondrial respiration and ATP production. ${ }^{112}$ Presenilin may regulate calcium levels of the ER and mitochondria, and thereby, the activity of both the mitochondria and the lysosome's calcium-dependent proteases. If fAD mutations impair this function, it would directly imply presenilin loss of function as responsible for proteostatic breakdown. ${ }^{113}$

\section{Conclusions}

In this study, we asked the question how calcium interacts with presenilins in a membrane. Using molecular dynamics simulations of both PS1 and PS2 in complex with calcium in a realistic membrane model, we have identified four persistent $\mathrm{Ca}^{2+}$ binding sites. The four sites include one in HL2 situated towards the C-terminal of TM6, one in HL2 located towards the N-terminal of TM7, a site at the catalytic aspartate on TM7, and a site involving the PALP motif on TM9. Except for the catalytic aspartate of TM6, no prominent interaction existed with TM6. We observed that the residues of the PALP motif, in particular ALP, interacted with calcium at the N-terminal of TM9. The middle to C-terminal part of TM9 is highly water accessible and interacts with $\mathrm{Ca}^{2+}$. In addition, a poly-glutamate stretch containing seven glutamates in PS2 (a homologous region exists in PS1 with less glutamates) featured a very strong calcium binding site and existed in close proximity to TM7 during our simulations.

We did not observe any complete $\mathrm{Ca}^{2+}$ leak event, and thus our results do not support that presenilins function as actual calcium transport proteins, although this conclusion could be affected by force field and sampling timescale. We used the CHARMM36m force field optimized for the membrane proteins and for $\mathrm{Ca}^{2+}$ as the best available force field. Still, absolute $\mathrm{Ca}^{2+}$ affinities and the qualitative ability to bind calcium will be force-field dependent ${ }^{114}$ but the relative significance of sites within the same protein should not be equally so, as over-binding or underbinding tendencies will tend to cancel. We simulated sufficiently ( $1 \mu$ s for each of the 24 systems) to observe reversible $\mathrm{Ca}^{2+}$ movements, which indicate good local sampling of the sites. Although we observed large conformational changes in the transmembrane segments, the complete $\mathrm{Ca}^{2+}$ transfer might require more conformational changes than simulated here.

However, the four key $\mathrm{Ca}^{2+}$ sites that we identify are so persistent and typical of glutamateand aspartate-enriched calcium binding sites in general that calcium, if present, most likely interacts strongly with these sites. These sites may play a significant $\mathrm{Ca}^{2+}$ regulatory role by dampening HL2 motions and changing its conformation. Due to their location in HL2 and the 
active site required for auto-proteolytic maturation, and consistent movement between these two sites, we propose that calcium controls maturation of presenilin by conformational restriction of HL2. We speculate that presenilin maturation, which requires the entry of the loop into the active site, is prevented by calcium binding, thus preserving the immature calcium regulation function. Maturation, we propose, in contrast removes the calcium regulatory function. The regulatory function is proposed to act via HL2 interaction with other calcium transport proteins, rather than by actual transport through presenilin itself. We note that $\mathrm{Ca}^{2+}$ transfer between sites will depend on whether the receiving site is already occupied. Our study thus does not rule out that multiple $\mathrm{Ca}^{2+}$ can bind at the same time.

We also find that Asp protonation prevents $\mathrm{Ca}^{2+}$ from entering the catalytic site. We therefore suggest that the calcium regulatory function via HL2 proposed above is $\mathrm{pH}$-dependent. Low $\mathrm{pH}$, characteristic of the lysosome, may prevent calcium binding to the central catalytic site, thereby ensuring that it binds to HL2; this calcium binding dampens HL2 motions and we propose that calcium-bound HL2 forms a recognition site with calcium transport proteins to facilitate their calcium transport. This hypothesis is supported by PROPKA calculations indicating that lysosomal $\mathrm{pH}$ (4-5) comfortably effectuates this change in protonation state (Tables S1-S2). Both calcium and presenilin are required for lysosome proteolytic function, ${ }^{88,89}$ and we believe our structural dynamics provide a plausible model for these observations.

\section{Supporting Information}

The supporting information contains the electrostatic maps of PS2 (Fig. S1), deuterium order parameter plots (Fig. S2), partial densities of membrane groups and TIP3P (Fig. S3), average SASA with standard deviation (Fig. S4), time dependent plots of RMSD, $R_{g}$ and SASA (Fig. S5), HL2 loop motion (Fig. S6), porcupine plots (Fig. S7 and S8), PCA plots using initial 500 ns trajectories (Fig. S9), distance analysis (Fig. S10 and S11), percent interaction plots (Figs. S12S14), MMGBSA $\Delta \mathrm{G}_{\text {bind }}$ Coulombic energies (Fig. S15), comparison of PS2 initial conformers with representative MD structures (Fig S16), protonation states of catalytic aspartates (Tables S1,S2 and S4) and calcium movement events (Table S3). The Supporting Information is available free of charge at https://pubs.acs.org/

\section{Funding}

The work was supported by the Danish Council for Independent Research | Natural Sciences (DFF), grant case 7016-00079B. 


\section{Author contributions}

RM and KPK designed the work. RM performed the simulations and wrote the first draft. KPK and RM analyzed results and wrote the main paper together.

\section{ORCID}

Rukmankesh Mehra: 0000-0001-6010-1514

Kasper P. Kepp: 0000-0002-6754-7348

\section{Acknowledgements}

The Danish Council for Independent Research | Natural Sciences (DFF), grant case 7016-00079B, is acknowledged for supporting this work. The financial support by the Novo Nordisk Foundation grant for the ROBUST-project is also acknowledged. We also thank the DTU Computing Center (DCC) and Centre for Scientific Computing Aarhus for the High-Performance Computing facility. 


\section{References}

(1) Goedert, M.; Spillantini, M. G. A Century of Alzheimer's Disease. Science 2006, 314 (2006), 777-781.

(2) Holtzman, D. M.; Morris, J. C.; Goate, A. M. Alzheimer's Disease: The Challenge of the Second Century. Science Translational Medicine. 2011, p 77sr1.

(3) Dartigues, J. F. Alzheimer's Disease: A Global Challenge for the 21st Century. Lancet Neurol. 2009, 8, 1082-1083.

(4) Blennow, K.; de Leon, M. J.; Zetterberg, H. Alzheimer's Disease. Lancet 2015, 368 (9533), 387-403.

(5) McKhann, G. M.; Knopman, D. S.; Chertkow, H.; Hyman, B. T.; Jack Jr., C. R.; Kawas, C. H.; Klunk, W. E.; Koroshetz, W. J.; Manly, J. J.; Mayeux, R.; et al. The Diagnosis of Dementia Due to Alzheimer's Disease: Recommendations from the National Institute on Aging-Alzheimer's Association Workgroups on Diagnostic Guidelines for Alzheimer's Disease. Alzheimer's Dement. 2011, 7 (3), 263-269.

(6) Karlawish, J. Addressing the Ethical, Policy, and Social Challenges of Preclinical Alzheimer Disease. Neurology 2011, 77 (15), 1487-1493.

(7) Sorrentino, P.; Iuliano, A.; Polverino, A.; Jacini, F.; Sorrentino, G. The Dark Sides of Amyloid in Alzheimer's Disease Pathogenesis. FEBS Lett. 2014, 588 (5), 641-652.

(8) Graham, W. V.; Bonito-Oliva, A.; Sakmar, T. P. Update on Alzheimer's Disease Therapy and Prevention Strategies. Annu. Rev. Med. 2017, 68 (1), 413-430.

(9) Hardy, J. Alzheimer's Disease: The Amyloid Cascade Hypothesis - An Update and Reappraisal. J. Alzheimer's Dis. 2006, 9 (3), 151-153.

(10) Selkoe, D. J.; Hardy, J. The Amyloid Hypothesis of Alzheimer's Disease at 25 Years. EMBO Mol. Med. 2016, 8 (6), 595-608.

(11) Lee, H.; Casadesus, G.; Zhu, X.; Takeda, A.; Perry, G.; Smith, M. A. Challenging the Amyloid Cascade Hypothesis: Senile Plaques and Amyloid- $\beta$ as Protective Adaptations to Alzheimer Disease. Ann. N. Y. Acad. Sci. 2004, 1019 (1), 1-4.

(12) Kepp, K. P. Ten Challenges of the Amyloid Hypothesis of Alzheimer's Disease. J. Alzheimer's Dis. 2017, 55 (2), 447-457. 
(13) Herrup, K. The Case for Rejecting the Amyloid Cascade Hypothesis. Nat Neurosci 2015, 794-799.

(14) Chiang, C.-J.; Yip, P.-K.; Wu, S.-C.; Lu, C.-S.; Liou, C.-W.; Liu, H.-C.; Liu, C.-K.; Chu, C.-H.; Hwang, C.-S.; Sung, S.-F.; et al. Midlife risk factors for subtypes of dementia: A nested case-control study in Taiwan. Am. J. Geriatr. Psychiatry 2007, 15 (9), 762-771.

(15) Kepp, K. P. A Quantitative Model of Human Neurodegenerative Diseases Involving Protein Aggregation. Neurobiol. Aging 2019, 80, 46-55.

(16) Brown, G. C. The Endotoxin Hypothesis of Neurodegeneration. J. Neuroinflammation 2019, 16 (1), 180.

(17) Rosenblum, W. I. Why Alzheimer Trials Fail: Removing Soluble Oligomeric Beta Amyloid Is Essential, Inconsistent, and Difficult. Neurobiol. Aging 2014, 35 (5), 969-974.

(18) De Strooper, B. Lessons from a Failed $\gamma$-Secretase Alzheimer Trial. Cell 2014, 159 (4), $721-726$.

(19) Teich, A. F.; Arancio, O. Is the Amyloid Hypothesis of Alzheimer's Disease Therapeutically Relevant? Biochem. J. 2012, 446, 165-177.

(20) Golde, T. E.; Schneider, L. S.; Koo, E. H. Anti-A $\beta$ Therapeutics in Alzheimer's Disease: The Need for a Paradigm Shift. Neuron 2011, 69 (2), 203-213.

(21) De Strooper, B.; Chávez Gutiérrez, L. Learning by Failing: Ideas and Concepts to Tackle $\gamma$-Secretases in Alzheimer's Disease and Beyond. Annu. Rev. Pharmacol. Toxicol. 2015, 55 (1), 419-437.

(22) Masters, C. L.; Gajdusek, D. C.; Gibbs, C. J. J. The Familial Occurrence of CreutzfeldtJakob Disease and Alzheimer's Disease. Brain 1981, 104 (3), 535-558.

(23) Puzzo, D.; Gulisano, W.; Palmeri, A.; Arancio, O. Rodent Models for Alzheimer's Disease Drug Discovery. Expert Opin. Drug Discov. 2015, 10 (7), 703-711.

(24) Goate, A.; Chartier-Harlin, M. C.; Mullan, M.; Brown, J.; Crawford, F.; Fidani, L.; Giuffra, L.; Haynes, A.; Irving, N.; James, L. Segregation of a Missense Mutation in the Amyloid Precursor Protein Gene with Familial Alzheimer's Disease. Nature 1991, 349 (6311), 704-706.

(25) Sherrington, R.; Rogaev, E. I.; Liang, Y.; Rogaeva, E. A.; Levesque, G.; Ikeda, M.; Chi, H.; Lin, C.; Li, G.; Holman, K.; et al. Cloning of a Gene Bearing Missense Mutations in 
Early-Onset Familial Alzheimer's Disease. Nature 1995, 375 (6534), 754-760.

(26) Levy-Lahad, E.; Wasco, W.; Poorkaj, P.; Romano, D. M.; Oshima, J.; Pettingell, W. H.; Yu, C. E.; Jondro, P. D.; Schmidt, S. D.; Wang, K.; et al. Candidate Gene for the Chromosome 1 Familial Alzheimer's Disease Locus. Science (80-. ). 1995, 269 (5226), 973-977.

(27) Hollingworth, P.; Harold, D.; Jones, L.; Owen, M. J.; Williams, J. Alzheimer's Disease Genetics: Current Knowledge and Future Challenges. Int. J. Geriatr. Psychiatry 2011, 26, 793-802.

(28) Ryman, D. C.; Acosta-Baena, N.; Aisen, P. S.; Bird, T.; Danek, A.; Fox, N. C.; Goate, A.; Frommelt, P.; Ghetti, B.; Langbaum, J. B. S.; et al. Symptom Onset in Autosomal Dominant Alzheimer Disease: A Systematic Review and Meta-Analysis. Neurology 2014, 83 (3), 253-260.

(29) Campion, D.; Dumanchin, C.; Hannequin, D.; Dubois, B.; Belliard, S.; Puel, M.; ThomasAnterion, C.; Michon, A.; Martin, C.; Charbonnier, F.; et al. Early-Onset Autosomal Dominant Alzheimer Disease: Prevalence, Genetic Heterogeneity, and Mutation Spectrum. Am. J. Hum. Genet. 1999, 65 (3), 664-670.

(30) Wolfe, M. S. Processive Proteolysis by $\gamma$-Secretase and the Mechanism of Alzheimer's Disease. Biol. Chem. 2012, 393, 899-905.

(31) Vassar, R.; Bennett, B. D.; Babu-Khan, S.; Kahn, S.; Mendiaz, E. A.; Denis, P.; Teplow, D. B.; Ross, S.; Amarante, P.; Loeloff, R.; et al. Beta-Secretase Cleavage of Alzheimer's Amyloid Precursor Protein by the Transmembrane Aspartic Protease BACE. Science 1999, 286 (5440), 735-741.

(32) De Strooper, B.; Saftig, P.; Craessaerts, K.; Vanderstichele, H.; Guhde, G.; Annaert, W.; Von Figura, K.; Van Leuven, F. Deficiency of Presenilin-1 Inhibits the Normal Cleavage of Amyloid Precursor Protein. Nature 1998, 391 (6665), 387-390.

(33) Wolfe, M. S.; Xia, W.; Ostaszewski, B. L.; Diehl, T. S.; Kimberly, W. T.; Selkoe, D. J. Two Transmembrane Aspartates in Presenilin-1 Required for Presenilin Endoproteolysis and Gamma-Secretase Activity. Nature 1999, 398 (6727), 513-517.

(34) Naruse, S.; Thinakaran, G.; Luo, J. J.; Kusiak, J. W.; Tomita, T.; Iwatsubo, T.; Qian, X.; Ginty, D. D.; Price, D. L.; Borchelt, D. R.; et al. Effects of PS1 Deficiency on Membrane Protein Trafficking in Neurons. Neuron 1998, 21 (5), 1213-1221. 
(35) Serneels, L.; Dejaegere, T.; Craessaerts, K.; Horré, K.; Jorissen, E.; Tousseyn, T.; Hébert, S.; Coolen, M.; Martens, G.; Zwijsen, A.; et al. Differential Contribution of the Three Aph1 Genes to $\gamma$-Secretase Activity in Vivo. Proc. Natl. Acad. Sci. United States Am. 2005, 102 (5), 1719-1724.

(36) Baumeister, R.; Leimer, U.; Zweckbronner, I.; Jakubek, C.; Grunberg, J.; Haass, C. Human Presenilin-1, but Not Familial Alzheimer's Disease (FAD) Mutants, Facilitate Caenorhabditis Elegans Notch Signalling Independently of Proteolytic Processing. Genes Funct. 1997, 1 (2), 149-159.

(37) Sun, L.; Zhou, R.; Yang, G.; Shi, Y. Analysis of 138 Pathogenic Mutations in Presenilin-1 on the in Vitro Production of A $\beta 42$ and A $\beta 40$ Peptides by $\gamma$-Secretase. Proc. Natl. Acad. Sci. 2016, 114 (4), E476-E485.

(38) Somavarapu, A. K.; Kepp, K. P. Loss of Stability and Hydrophobicity of Presenilin 1 Mutations Causing Alzheimer's Disease. J. Neurochem. 2016, 137, 101-111.

(39) Tang, N.; Kepp, K. P. A $342 / A \beta 40$ Ratios of Presenilin 1 Mutations Correlate with Clinical Onset of Alzheimer's Disease. J. Alzheimer's Dis. 2018, 66 (3), 939-945.

(40) Khachaturian, Z. S. Hypothesis on the Regulation of Cytosol Calcium Concentration and the Aging Brain. Neurobiol. Aging 1987, 8 (4), 345-346.

(41) Tu, H.; Nelson, O.; Bezprozvanny, A.; Wang, Z.; Lee, S.-F.; Hao, Y.-H.; Serneels, L.; De Strooper, B.; Yu, G.; Bezprozvanny, I. Presenilins Form ER Ca2+ Leak Channels, a Function Disrupted by Familial Alzheimer's Disease-Linked Mutations. Cell 2006, 126 (5), 981-993.

(42) Nelson, O.; Supnet, C.; Tolia, A.; Horré, K.; De Strooper, B.; Bezprozvanny, I. Mutagenesis Mapping of the Presenilin 1 Calcium Leak Conductance Pore. J. Biol. Chem. 2011, 286 (25), 22339-22347.

(43) Nelson, O.; Tu, H.; Lei, T.; Bentahir, M.; De Strooper, B.; Bezprozvanny, I. Familial Alzheimer Disease-Linked Mutations Specifically Disrupt $\mathrm{Ca}^{2+}$ Leak Function of Presenilin 1. J. Clin. Invest. 2007, 117(5), 1230-1239.

(44) Das, H. K.; Tchedre, K.; Mueller, B. Repression of Transcription of Presenilin-1 Inhibits $\gamma$-Secretase Independent ER $\mathrm{Ca}^{2+}$ Leak That Is Impaired by FAD Mutations. $J$. Neurochem. 2012, 122(3), 487-500.

(45) Mattson, M. P. ER Calcium and Alzheimer's Disease: In a State of Flux. Sci. Signal. 
2010, 3 (114), pe10.

(46) Ho, A.; Shen, J. Presenilins in Synaptic Function and Disease. Trends Mol. Med. 2011, 17(11), 617-624.

(47) Woods, N. K.; Padmanabhan, J. Neuronal Calcium Signaling and Alzheimer's Disease. Adv. Exp. Med. Biol. 2012, 740, 1193-1217.

(48) Leissring, M. A.; Yamasaki, T. R.; Wasco, W.; Buxbaum, J. D.; Parker, I.; LaFerla, F. M. Calsenilin Reverses Presenilin-Mediated Enhancement of Calcium Signaling. Proc. Natl. Acad. Sci. U. S. A. 2000, 97 (15), 8590-8593.

(49) Wu, B.; Yamaguchi, H.; Lai, F. A.; Shen, J. Presenilins Regulate Calcium Homeostasis and Presynaptic Function via Ryanodine Receptors in Hippocampal Neurons. Proc. Natl. Acad. Sci. U. S. A. 2013, 110(37), 15091-15096.

(50) Greotti, E.; Capitanio, P.; Wong, A.; Pozzan, T.; Pizzo, P.; Pendin, D. Familial Alzheimer's Disease-Linked Presenilin Mutants and Intracellular Ca2+ Handling: A Single-Organelle, FRET-Based Analysis. Cell Calcium 2019, 79, 44-56.

(51) Zatti, G.; Burgo, A.; Giacomello, M.; Barbiero, L.; Ghidoni, R.; Sinigaglia, G.; Florean, C.; Bagnoli, S.; Binetti, G.; Sorbi, S. Presenilin Mutations Linked to Familial Alzheimer's Disease Reduce Endoplasmic Reticulum and Golgi Apparatus Calcium Levels. Cell Calcium 2006, 39 (6), 539-550.

(52) Li, X.; Dang, S.; Yan, C.; Gong, X.; Wang, J.; Shi, Y. Structure of a Presenilin Family Intramembrane Aspartate Protease. Nature 2013, 493 (7430), 56-61.

(53) Chang, Y.; Bruni, R.; Kloss, B.; Assur, Z.; Kloppmann, E.; Rost, B.; Hendrickson, W. A.; Liu, Q. Structural Basis for a PH-Sensitive Calcium Leak across Membranes. Science 2014, 344 (6188), 1131-1135.

(54) Guo, Q.; Furukawa, K.; Sopher, B. L.; Pham, D. G.; Xie, J.; Robinson, N.; Martin, G. M.; Mattson, M. P. Alzheimer's PS-1 Mutation Perturbs Calcium Homeostasis and Sensitizes PC12 Cells to Death Induced by Amyloid Beta-Peptide. Neuroreport 1996, 8 (1), 379383.

(55) Mattson, M. P.; Cheng, B.; Culwell, A. R.; Esch, F. S.; Lieberburg, I.; Rydel, R. E. Evidence for Excitoprotective and Intraneuronal Calcium-Regulating Roles for Secreted Forms of the Beta-Amyloid Precursor Protein. Neuron 1993, 10 (2), 243-254. 
(56) Thinakaran, G.; Sisodia, S. S. Presenilins and Alzheimer Disease: The Calcium Conspiracy. Nat. Neurosci. 2006, 9(11), 1354-1355.

(57) Shilling, D.; Mak, D.-O. D.; Kang, D. E.; Foskett, J. K. Lack of Evidence for Presenilins as Endoplasmic Reticulum Ca2+ Leak Channels. J. Biol. Chem. 2012, 287 (14), 1093310944.

(58) Cheung, K. H.; Shineman, D.; Müller, M.; Cárdenas, C.; Mei, L.; Yang, J.; Tomita, T.; Iwatsubo, T.; Lee, V. M. Y.; Foskett, J. K. Mechanism of Ca2+ Disruption in Alzheimer's Disease by Presenilin Regulation of InsP3 Receptor Channel Gating. Neuron 2008, 58(6), $871-883$.

(59) Green, K. N.; LaFerla, F. M. Linking Calcium to A $\beta$ and Alzheimer's Disease. Neuron 2008, 59 (2), 190-194.

(60) Cheung, K. H.; Mei, L.; Mak, D. O. D.; Hayashi, I.; Iwatsubo, T.; Kang, D. E.; Foskett, J. K. Gain-of-Function Enhancement of IP3 Receptor Modal Gating by Familial Alzheimer's Disease-Linked Presenilin Mutants in Human Cells and Mouse Neurons. Sci. Signal. 2010, 3(114), ra22-ra22.

(61) Zhang, C.; Wu, B.; Beglopoulos, V.; Wines-Samuelson, M.; Zhang, D.; Dragatsis, I.; Südhof, T. C.; Shen, J. Presenilins Are Essential for Regulating Neurotransmitter Release. Nature 2009, 460(7255), 632-636.

(62) Green, K. N.; Demuro, A.; Akbari, Y.; Hitt, B. D.; Smith, I. F.; Parker, I.; LaFerla, F. M. SERCA Pump Activity Is Physiologically Regulated by Presenilin and Regulates Amyloid $\beta$ Production. J. Cell Biol. 2008, 181(7), 1107-1116.

(63) LaFerla, F. M. Calcium Dyshomeostasis and Intracellular Signalling in Alzheimer's Disease. Nat. Rev. Neurosci. 2002, 3 (11), 862.

(64) Dehury, B.; Tang, N.; Kepp, K. P. Insights into Membrane-Bound Presenilin 2 from AllAtom Molecular Dynamics Simulations. J. Biomol. Struct. Dyn. 2019, 1-15.

(65) Sali, A.; Blundell, T. L. Comparative Protein Modelling by Satisfaction of Spatial Restraints. J. Mol. Biol. 1993, 234 (3), 779-815.

(66) Webb, B.; Sali, A. Protein Structure Modeling with MODELLER. In Methods in Molecular Biology; Humana Press, New York, NY, 2017; Vol. 1654, pp 39-54.

(67) Dehury, B.; Tang, N.; Blundell, T. L.; Kepp, K. P. Structure and Dynamics of $\gamma$-Secretase 
with Presenilin 2 Compared to Presenilin 1. RSC Adv. 2019, 9 (36), 20901-20916.

(68) Aguayo-Ortiz, R.; Dominguez, L. Simulating the $\gamma$-Secretase Enzyme: Recent Advances and Future Directions. Biochimie 2018, 147, 130-135.

(69) Søndergaard, C. R.; Olsson, M. H. M.; Rostkowski, M.; Jensen, J. H. Improved Treatment of Ligands and Coupling Effects in Empirical Calculation and Rationalization of $\mathrm{p} \mathrm{K} \mathrm{a}$ Values. J. Chem. Theory Comput. 2011, 7(7), 2284-2295.

(70) Olsson, M. H. M.; Søndergaard, C. R.; Rostkowski, M.; Jensen, J. H. PROPKA3: Consistent Treatment of Internal and Surface Residues in Empirical p K a Predictions. $J$. Chem. Theory Comput. 2011, 7 (2), 525-537.

(71) Somavarapu, A. K.; Kepp, K. P. The Dynamic Mechanism of Presenilin-1 Function: Sensitive Gate Dynamics and Loop Unplugging Control Protein Access. Neurobiol. Dis. 2016, 89, 147-156.

(72) Somavarapu, A. K.; Kepp, K. P. Membrane Dynamics of $\gamma$-Secretase Provides a Molecular Basis for $\beta$-Amyloid Binding and Processing. ACS Chem. Neurosci. 2017, 8 (11), 2424-2436.

(73) Dehury, B.; Tang, N.; Kepp, K. P. Molecular Dynamics of C99-Bound $\gamma$-Secretase Reveal Two Binding Modes with Distinct Compactness, Stability, and Active-Site Retention: Implications for A $\beta$ Production. Biochem. J. 2019, 476 (7), 1173-1189.

(74) Mehra, R.; Dehury, B.; Kepp, K. P. Cryo-Temperature Effects on Membrane Protein Structure and Dynamics. Phys. Chem. Chem. Phys. 2020, 22, 5427-5438.

(75) Schrödinger; D. E. Shaw Research. Desmond Molecular Dynamics System; Release 20183; Schrödinger, LLC: New York, US, 2018.

(76) Sato, C.; Takagi, S.; Tomita, T.; Iwatsubo, T. The C-Terminal PAL Motif and Transmembrane Domain 9 of Presenilin 1 Are Involved in the Formation of the Catalytic Pore of the $\gamma$-Secretase. J. Neurosci. 2008, 28(24), 6264-6271.

(77) Lomize, M. A.; Pogozheva, I. D.; Joo, H.; Mosberg, H. I.; Lomize, A. L. OPM Database and PPM Web Server: Resources for Positioning of Proteins in Membranes. Nucleic Acids Res. 2012, 40 (D1), D370-D376.

(78) Jo, S.; Kim, T.; Iyer, V. G.; Im, W. CHARMM-GUI: A Web-Based Graphical User Interface for CHARMM. J. Comput. Chem. 2008, 29 (11), 1859-1865. 
(79) Klauda, J. B.; Venable, R. M.; Freites, J. A.; O’Connor, J. W.; Tobias, D. J.; MondragonRamirez, C.; Vorobyov, I.; MacKerell, A. D.; Pastor, R. W. Update of the CHARMM AllAtom Additive Force Field for Lipids: Validation on Six Lipid Types. J. Phys. Chem. B 2010, 114 (23), 7830-7843.

(80) Huang, J.; Rauscher, S.; Nawrocki, G.; Ran, T.; Feig, M.; De Groot, B. L.; Grubmüller, H.; MacKerell, A. D. CHARMM36m: An Improved Force Field for Folded and Intrinsically Disordered Proteins. Nat. Methods 2016, 14 (1), 71-73.

(81) Berendsen, H. J. C.; van der Spoel, D.; van Drunen, R. GROMACS: A Message-Passing Parallel Molecular Dynamics Implementation. Comput. Phys. Commun. 1995, 91 (1-3), $43-56$.

(82) Van Der Spoel, D.; Lindahl, E.; Hess, B.; Groenhof, G.; Mark, A. E.; Berendsen, H. J. C. GROMACS: Fast, Flexible, and Free. J. Comput. Chem. 2005, 26 (16), 1701-1718.

(83) Berendsen, H. J. C.; Postma, J. P. M.; van Gunsteren, W. F.; DiNola, A.; Haak, J. R. Molecular Dynamics with Coupling to an External Bath. J. Chem. Phys. 1984, 81 (8), 3684-3690.

(84) Evans, D. J.; Holian, B. L. The Nose-Hoover Thermostat. J. Chem. Phys. 1985, 83(8), 4069-4074.

(85) Parrinello, M.; Rahman, A. Polymorphic Transitions in Single Crystals: A New Molecular Dynamics Method. J. Appl. Phys. 1981, 52 (12), 7182-7190.

(86) Seelig, J.; Browning, J. L. General Features of Phospholipid Conformation in Membranes. Febs Lett. 1978, 92 (1), 41-44.

(87) Zwier, M. C.; Chong, L. T. Reaching Biological Timescales with All-Atom Molecular Dynamics Simulations. Curr. Opin. Pharmacol. 2010, 10 (6), 745-752.

(88) Lee, J.-H.; Yu, W. H.; Kumar, A.; Lee, S.; Mohan, P. S.; Peterhoff, C. M.; Wolfe, D. M.; Martinez-Vicente, M.; Massey, A. C.; Sovak, G.; et al. Lysosomal Proteolysis and Autophagy Require Presenilin 1 and Are Disrupted by Alzheimer-Related PS1 Mutations. Cell 2010, 141 (7), 1146-1158.

(89) McBrayer, M.; Nixon, R. A. Lysosome and Calcium Dysregulation in Alzheimer's Disease: Partners in Crime. Biochem. Soc. Trans. 2013, 41 (6), 1495-1502.

(90) Bai, X.; Yan, C.; Yang, G.; Lu, P.; Sun, L.; Zhou, R.; Scheres, S. H. W.; Shi, Y. An 
Atomic Structure of Human $\gamma$-Secretase. Nature 2015, 525, 212-218.

(91) Tolia, A.; Horré, K.; De Strooper, B. Transmembrane Domain 9 of Presenilin Determines the Dynamic Conformation of the Catalytic Site of $\gamma$-Secretase. J. Biol. Chem. 2008, 283 (28), 19793-19803.

(92) Nelson, O.; Supnet, C.; Liu, H.; Bezprozvanny, I. Familial Alzheimer's Disease Mutations in Presenilins: Effects on Endoplasmic Reticulum Calcium Homeostasis and Correlation with Clinical Phenotypes. J. Alzheimer's Dis. 2010, 21 (3), 781-793.

(93) Zhang, H.; Sun, S.; Herreman, A.; De Strooper, B.; Bezprozvanny, I. Role of Presenilins in Neuronal Calcium Homeostasis. J. Neurosci. 2010, 30 (25), 8566-8580.

(94) Morohashi, Y.; Kan, T.; Tominari, Y.; Fuwa, H.; Okamura, Y.; Watanabe, N.; Sato, C.; Natsugari, H.; Fukuyama, T.; Iwatsubo, T.; et al. C-Terminal Fragment of Presenilin Is the Molecular Target of a Dipeptidic $\gamma$-Secretase-Specific Inhibitor DAPT (N-[N-(3,5Difluorophenacetyl)-L- Alanyl]-S-Phenylglycine t-Butyl Ester). J. Biol. Chem. 2006, 281(21), 14670-14676.

(95) Rastelli, G.; Del Rio, A.; Degliesposti, G.; Sgobba, M. Fast and Accurate Predictions of Binding Free Energies Using MM-PBSA and MM-GBSA. J. Comput. Chem. 2010, 31(4), 797-810.

(96) Fisher, S. J.; Wilkinson, J.; Henchman, R. H.; Helliwell, J. R. An Evaluation Review of the Prediction of Protonation States in Proteins versus Crystallographic Experiment. In Perspectives in crystallography; Helliwell, J. R., Ed.; CRC Press: London, 2015; pp 101128.

(97) Skobeleva, K. V; Ryazantseva, M. A.; Stepanova, A. V; Wang, G.; Jana, N. R.;

Kaznacheyeva, E. V. Dominant Effect of Full-Length Presenilin-1 on the Enhancement of Store-Operated Calcium Entry. Biochem. (Moscow), Suppl. Ser. A Membr. Cell Biol. 2019, 13 (3), 253-259.

(98) Garrity, A. G.; Wang, W.; Collier, C. M.; Levey, S. A.; Gao, Q.; Xu, H. The Endoplasmic Reticulum, Not the PH Gradient, Drives Calcium Refilling of Lysosomes. Elife 2016, 5, e15887.

(99) Kepp, K. P. Alzheimer's Disease Due to Loss of Function: A New Synthesis of the Available Data. Prog. Neurobiol. 2016, 143, 36-60.

(100) Kepp, K. P. Alzheimer's Disease: How Metal Ions Define $\beta$-Amyloid Function. Coord. 
Chem. Rev. 2017, 351, 127-159.

(101) Gazda, K.; Kuznicki, J.; Wegierski, T. Knockdown of Amyloid Precursor Protein Increases Calcium Levels in the Endoplasmic Reticulum. Sci. Rep. 2017, 7 (1), 1-10.

(102) Zampese, E.; Fasolato, C.; Kipanyula, M. J.; Bortolozzi, M.; Pozzan, T.; Pizzo, P. Presenilin 2 Modulates Endoplasmic Reticulum (ER)-Mitochondria Interactions and Ca2+ Cross-Talk. Proc. Natl. Acad. Sci. 2011, 108 (7), 2777-2782.

(103) Celsi, F.; Pizzo, P.; Brini, M.; Leo, S.; Fotino, C.; Pinton, P.; Rizzuto, R. Mitochondria, Calcium and Cell Death: A Deadly Triad in Neurodegeneration. Biochim. Biophys. Acta Bioenerg. 2009, 1787(5), 335-344.

(104) Filadi, R.; Greotti, E.; Turacchio, G.; Luini, A.; Pozzan, T.; Pizzo, P. Presenilin 2 Modulates Endoplasmic Reticulum-Mitochondria Coupling by Tuning the Antagonistic Effect of Mitofusin 2. Cell Rep. 2016, 15 (10), 2226-2238.

(105) Robinson, K. S.; Clements, A.; Williams, A. C.; Berger, C. N.; Frankel, G. Bax Inhibitor 1 in Apoptosis and Disease. Oncogene 2011, 30 (21), 2391-2400.

(106) Wu, S.; Song, W.; Wong, C. C. L.; Shi, Y. Bax Inhibitor 1 Is a $\gamma$-Secretase-Independent Presenilin-Binding Protein. Proc. Natl. Acad. Sci. 2019, 116 (1), 141-147.

(107) Santos, R. X.; Correia, S. C.; Wang, X.; Perry, G.; Smith, M. A.; Moreira, P. I.; Zhu, X. Alzheimer's Disease: Diverse Aspects of Mitochondrial Malfunctioning. Int. J. Clin. Exp. Pathol. 2010, 3(6), 570.

(108) Swerdlow, R. H.; Burns, J. M.; Khan, S. M. The Alzheimer's Disease Mitochondrial Cascade Hypothesis. J. Alzheimer's Dis. 2010, 20(s2), S265-S279.

(109) Begley, J. G.; Duan, W.; Chan, S.; Duff, K.; Mattson, M. P. Altered Calcium Homeostasis and Mitochondrial Dysfunction in Cortical Synaptic Compartments of Presenilin-1 Mutant Mice. J. Neurochem. 1999, 72 (3), 1030-1039.

(110) Su, B.; Wang, X.; Zheng, L.; Perry, G.; Smith, M. A.; Zhu, X. Abnormal Mitochondrial Dynamics and Neurodegenerative Diseases. Biochim. Biophys. Acta - Mol. Basis Dis. 2010, 1802(1), 135-142.

(111) Area-Gomez, E.; De Groof, A. J. C.; Boldogh, I.; Bird, T. D.; Gibson, G. E.; Koehler, C. M.; Yu, W. H.; Duff, K. E.; Yaffe, M. P.; Pon, L. A.; et al. Presenilins Are Enriched in Endoplasmic Reticulum Membranes Associated with Mitochondria. Am. J. Pathol. 2009, 
175 (5), 1810-1816.

(112) Klec, C.; Madreiter-Sokolowski, C. T.; Stryeck, S.; Sachdev, V.; Duta-Mare, M.; Gottschalk, B.; Depaoli, M. R.; Rost, R.; Hay, J.; Waldeck-Weiermair, M. Glycogen Synthase Kinase 3 Beta Controls Presenilin-1-Mediated Endoplasmic Reticulum $\mathrm{Ca}^{2+}$ Leak Directed to Mitochondria in Pancreatic Islets and $\beta$-Cells. Cell. Physiol. Biochem. Int. J. Exp. Cell. Physiol. Biochem. Pharmacol. 2019, 52 (1), 57.

(113) Ashkavand, Z.; Sarasija, S.; Ryan, K. C.; Laboy, J. T.; Norman, K. R. Corrupted ERmitochondrial Calcium Homeostasis Promotes the Collapse of Proteostasis. Aging Cell 2019, e13065.

(114) Jensen, K. P. Improved Interaction Potentials for Charged Residues in Proteins. J. Phys. Chem. B 2008, 112 (6), 1820-1827. 


\section{TOC Graphic}

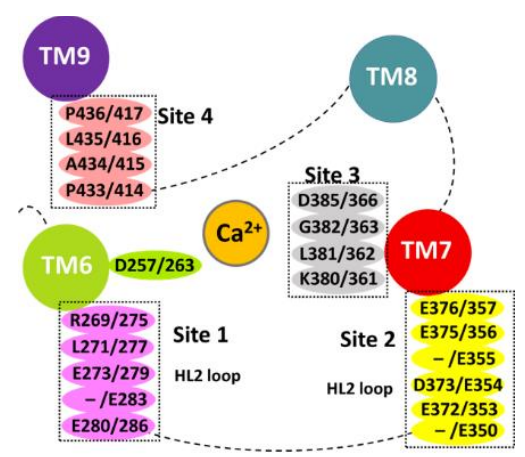



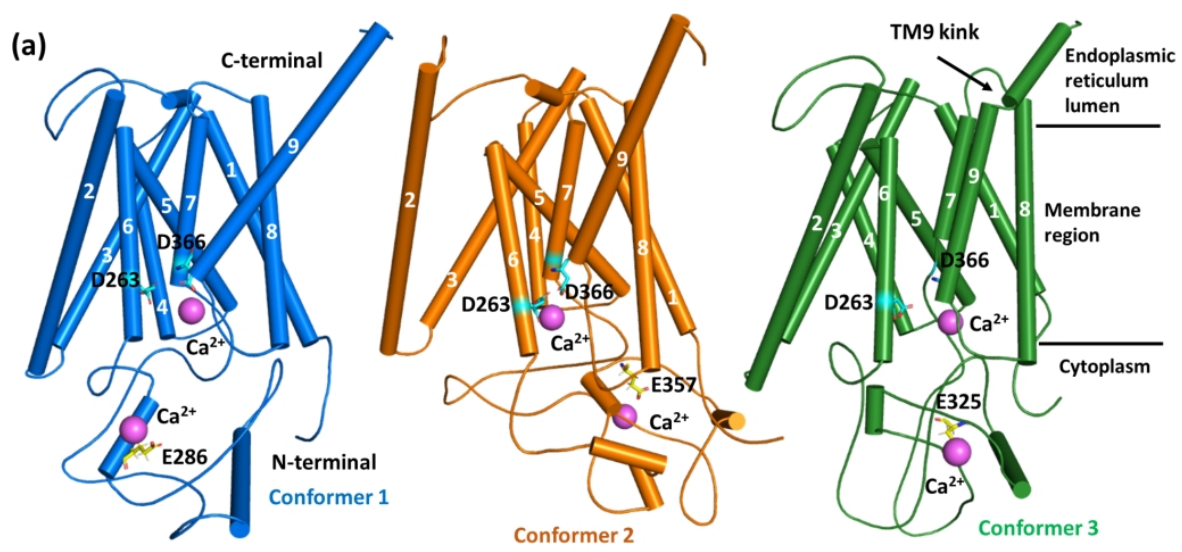

(b)

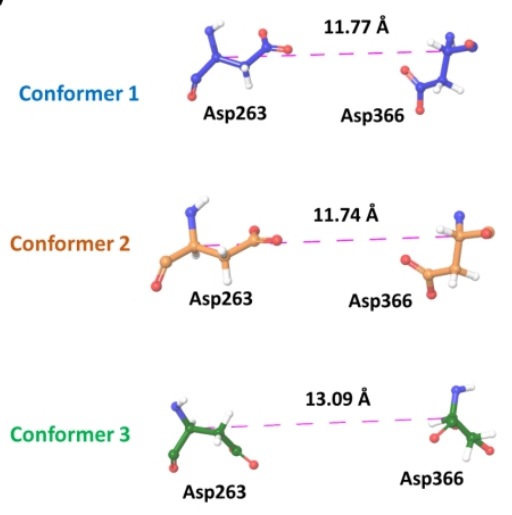

(c)

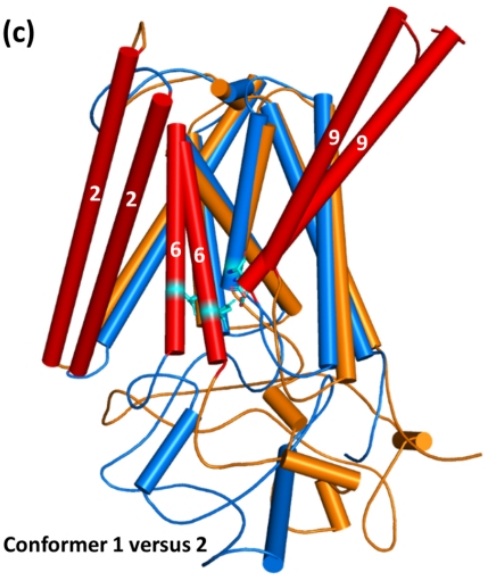

(d) 71 EELTLKYGAKHVIMLFVPVTLCMVVVVATIKSVSFYTRKDGOLIYTPFTEDTETVGORALHSILNAAIMISVIVVMTILLVVL 153

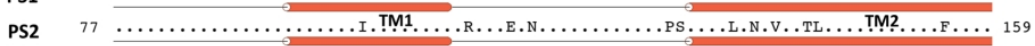

PS1 154 YKYRCYKVIHAWLIISSLLLLFFFSFIYLGEVFKTYNVAVDYITVALLIWNFGVVGMISIHWKGPLRLOOAYLIMISALMALV 236

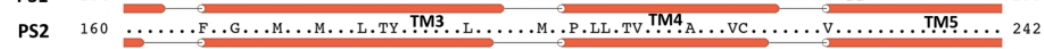

PS1 237 FIKYLPEWTAWLILAVISVYDLVAVLCPKGPLRMLVETAOERNETLFPALIYSSTMVWLVNMAEGDPEAORRVSKNSKYNAES 319

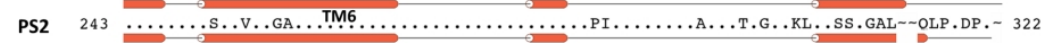

PS1 320 TERESODTVAENDDGGFSEEWEAORDSHLGPHRSTPESRAAVOELSSSILAGEDPEERGVKLGLGDFIFYSVLVGKASATASG 402

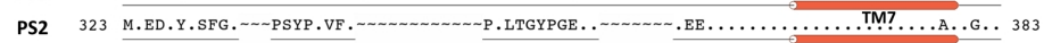

PS1 403 DWNTTIACFVAILIGLCLTLLLLAIFKKALPALPISITFGLVFYFATDYLVOPFMDOLAFHOFYI 467

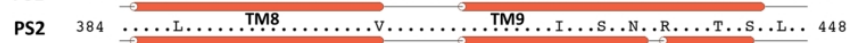

Figure 1

$169 \times 220 \mathrm{~mm}(300 \times 300 \mathrm{DPI})$ 
(a) PS1
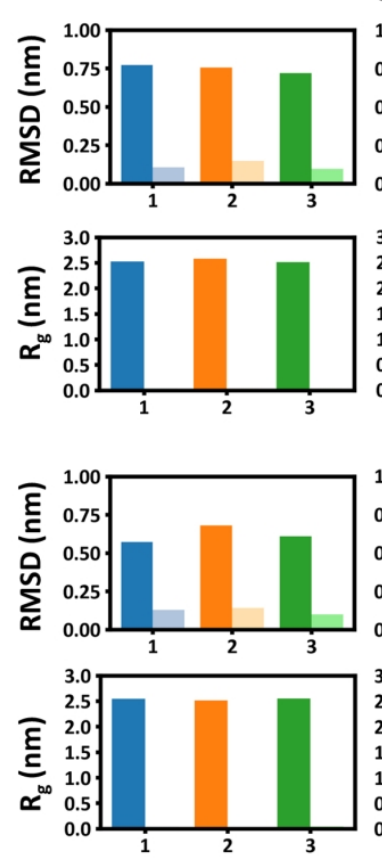

(b) PS1 D257-H $\mathrm{Ca}^{2+}$ placed near D385 in PS1 and D366 in PS2
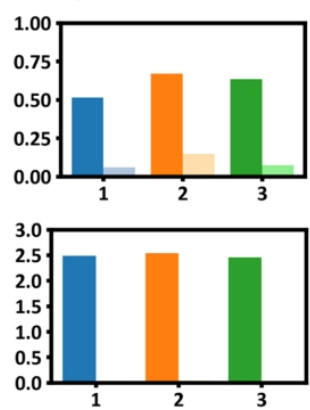

$\mathrm{Ca}^{2+}$ placed on HL2 loop
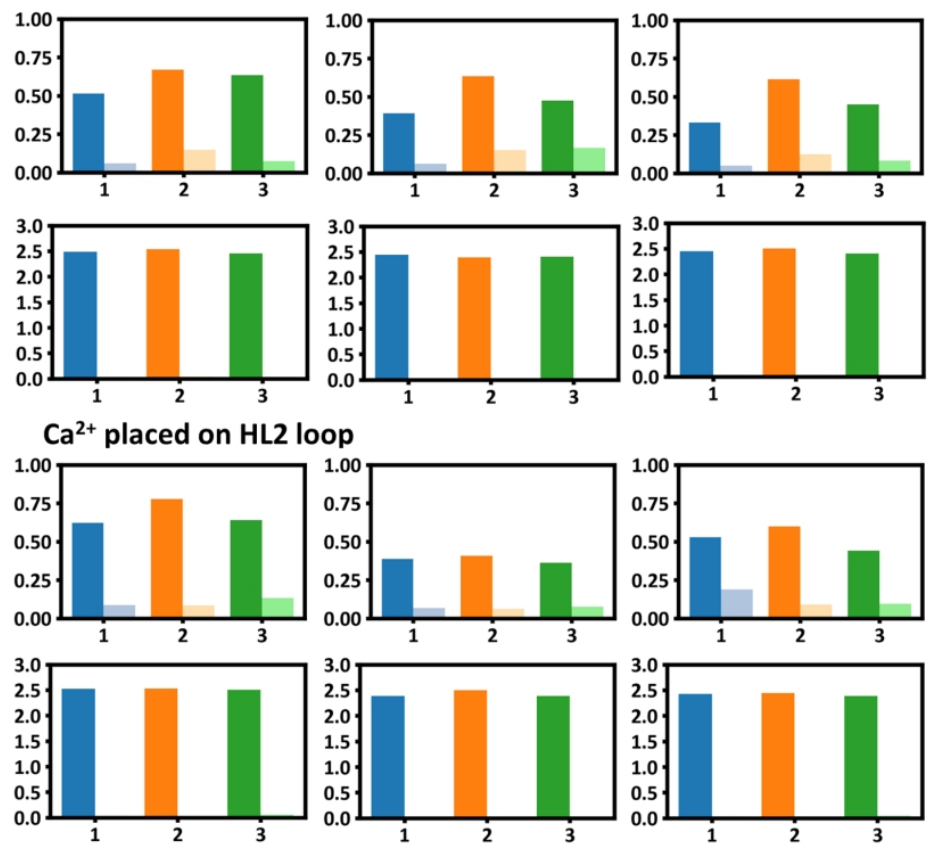

Figure 2

169x122mm (300 x 300 DPI) 
(a) PS1

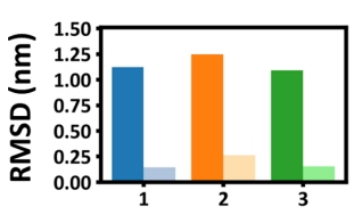

(b) PS1 D257-H $\mathrm{Ca}^{2+}$ placed near D385 in PS1 and D366 in PS2

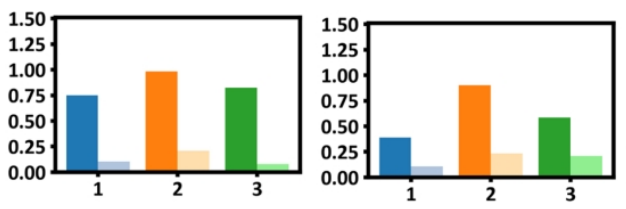

$\mathrm{Ca}^{2+}$ placed on HL2 loop

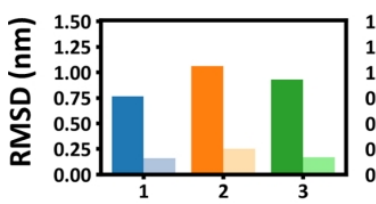

(d) PS2 D263-H
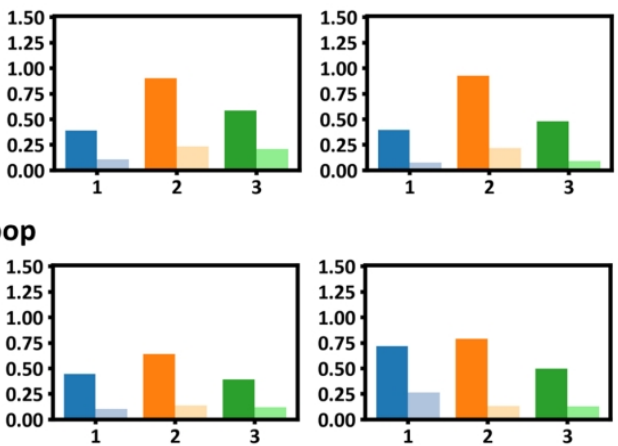

Figure 3

$169 \times 72 \mathrm{~mm}(300 \times 300 \mathrm{DPI})$ 
(a) PS1

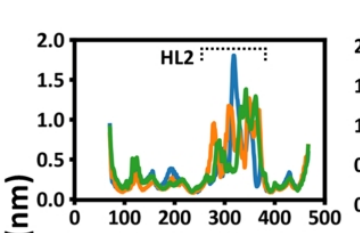

(b) PS1 D257-H

$\mathrm{Ca}^{2+}$ placed near D385 in PS1 and D366 in PS2
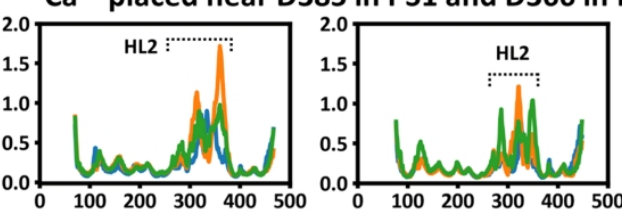

(d) PS2 D263-H

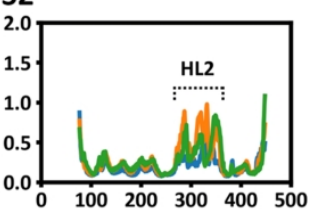

$\mathrm{Ca}^{2+}$ placed on HL2 loop
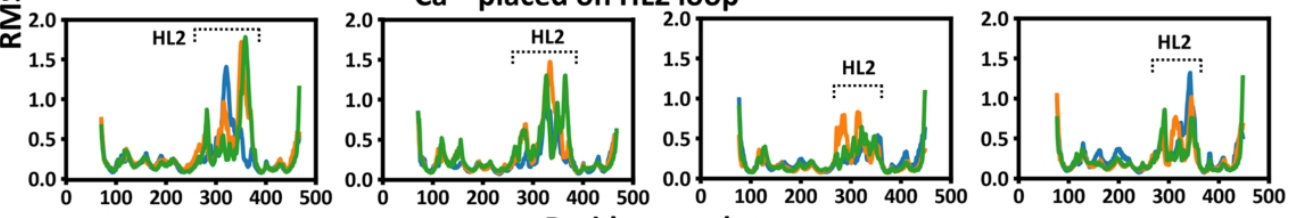

Residue number

Figure 4

$330 \times 143 \mathrm{~mm}(300 \times 300 \mathrm{DPI})$ 

(a) PS1
(b) PS1 D257-H
(c) PS2
(d) PS2 D263-H

500-1000 ns

$\mathrm{Ca}^{2+}$ placed near D385 in PS1 and D366 in PS2
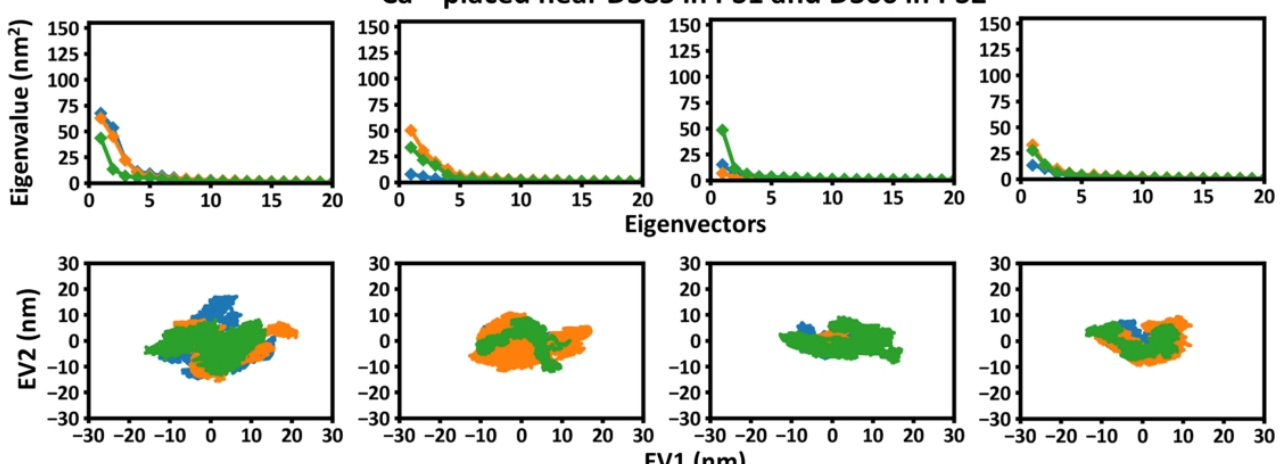

$\mathrm{Ca}^{2+}$ placed on HL2 loop
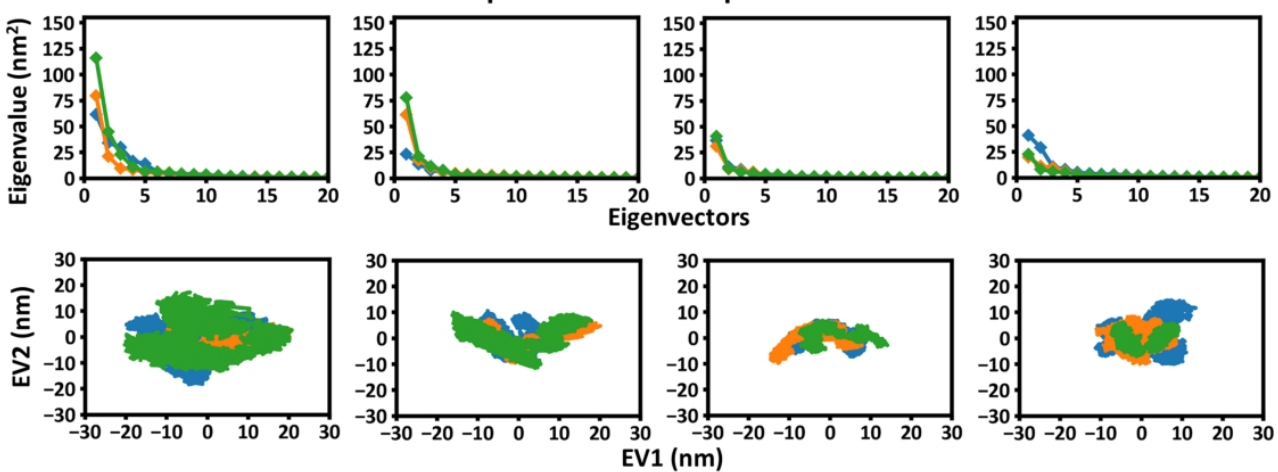

Figure 5

$224 \times 190 \mathrm{~mm}(300 \times 300 \mathrm{DPI})$ 
(a) PS1

(b) PS1 D257-H

(c) PS2

(d) PS2 D263-H

\section{$\mathrm{Ca}^{2+}$ placed near D385 in PS1 and D366 in PS2}

$\begin{array}{lll}\text { Replica } 1 & \text { No } & \text { No } \\ \text { Replica 2 } & \text { No } & \text { No } \\ \text { Replica 3 } & \text { CAT } \rightleftarrows \text { HL2 } & \text { CAT } \rightleftarrows \text { HL2 } \\ & \text { HL2 } \rightleftarrows \text { TIP3 } & \end{array}$

CAT $\rightleftarrows \mathrm{HL}^{1}$

CAT $\longrightarrow \mathrm{HL}^{1}$

10

11

$\mathrm{Ca}^{2+}$ placed on HL2 loop

$\begin{array}{lll}\text { Replica 1 } & \text { HL2 } \rightleftarrows \text { TIP3 } & \text { No } \\ \text { Replica 2 } & \text { HL2 } \rightleftarrows \text { TIP3 } & \text { HL2 } \rightleftarrows \text { TIP3 } \\ \text { Replica 3 } & \text { HL2 } \rightleftarrows \text { TIP3 } & \text { HL2 } \rightleftarrows \text { TIP3 }\end{array}$

No

$\mathrm{CAT} \longrightarrow \mathrm{HL}^{1}$

CAT $\longrightarrow \mathrm{HL}^{1}$

CAT $\rightleftarrows \mathrm{HL2}$

$\mathrm{HL} 2 \rightleftarrows \mathrm{TIP} 3$

$\mathrm{HL} 2 \rightleftarrows \mathrm{TIP} 3$

Figure 6

$169 \times 82 \mathrm{~mm}(300 \times 300$ DPI $)$ 
(a) PS1

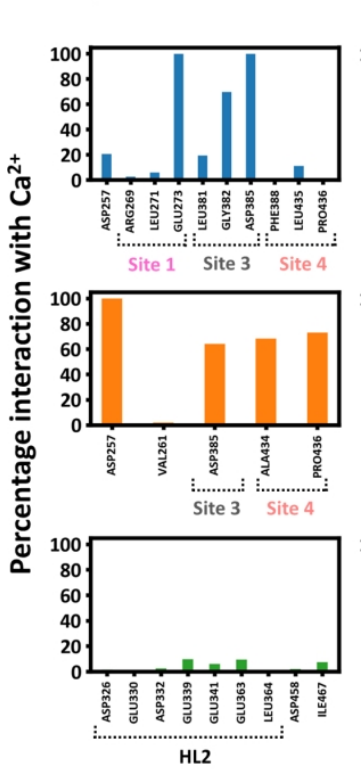

(b) PS1 D257-H

(c) PS2

$\mathrm{Ca}^{2+}$ placed near D385 in PS1 and D366 in PS2
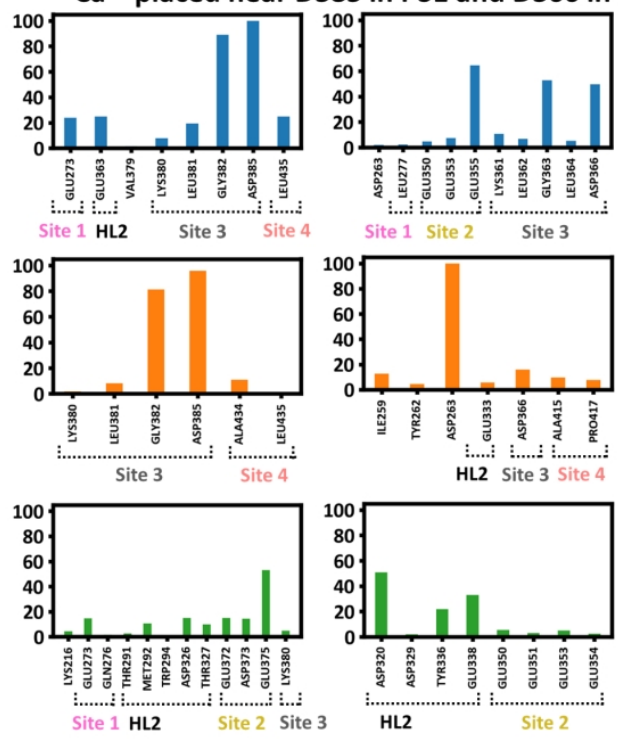

(d) PS2 D263-H
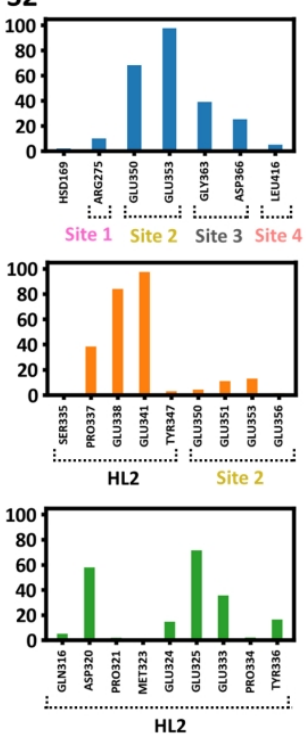

Figure 7

$169 \times 107 \mathrm{~mm}(300 \times 300$ DPI $)$ 
(a) PS1

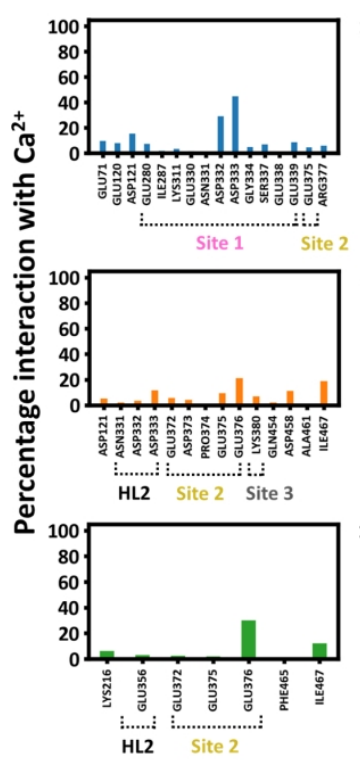

9

10

11

12

13

14

15

16

17

18

19

20

21

22

23

24

25

26

27

28

29

30

31

32

33

34

35

36

37

38

39

40

41

42

43

44

45

46

47

48

49

50

51

52

53

54

55

56

57

58

59

60

Figure 8 (b) PS1 D257-H $\mathrm{Ca}^{2+}$ placed on $\mathrm{HL} 2$ loop

(c) PS2
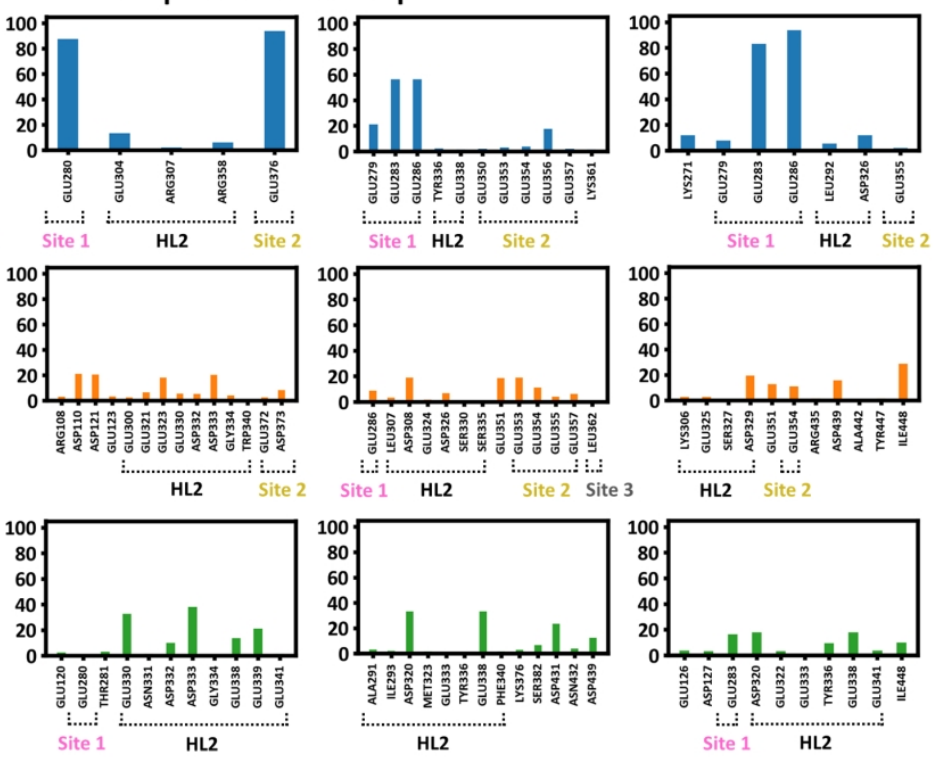

$169 \times 110 \mathrm{~mm}$ ( $300 \times 300$ DPI) 
(a) $\mathrm{Ca}^{2+}$ sites in presenilin

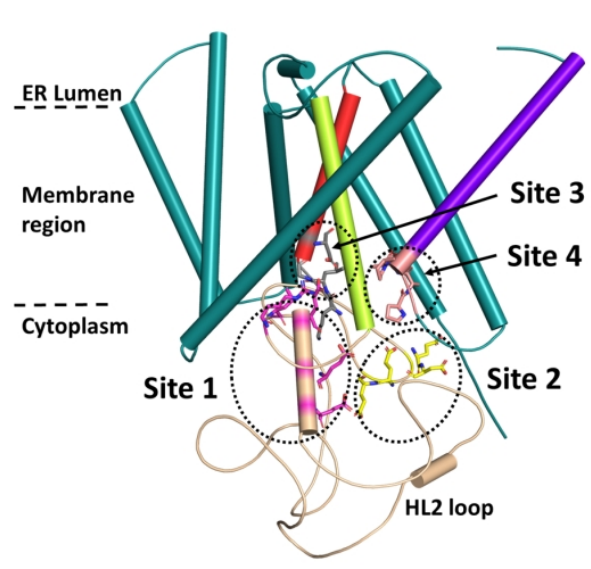

(c) PS1

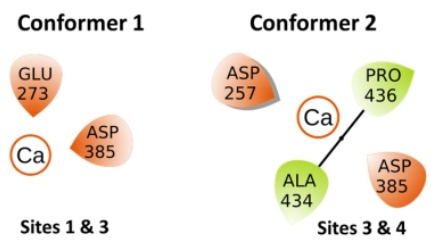

(e) PS2

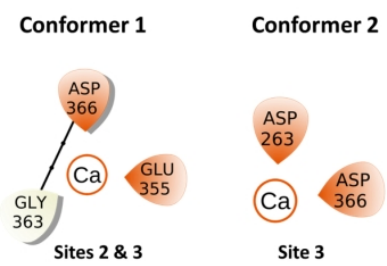

Conformer 3

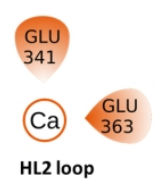

HL2 loop

\section{(b) Residues forming $\mathrm{Ca}^{2+}$ sites}

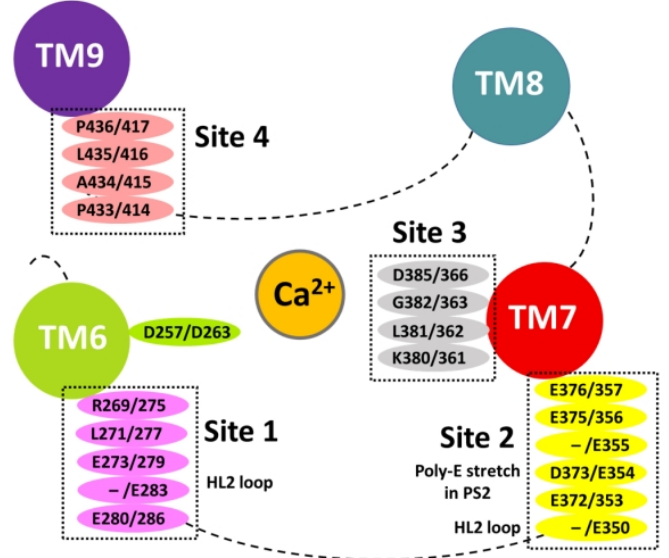

(d) PS1 D257-H
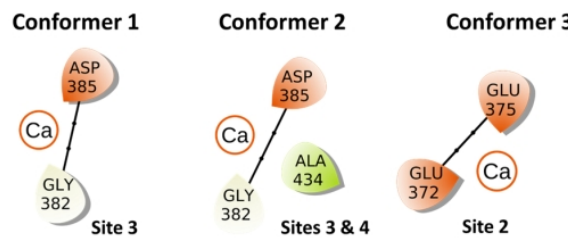

(f) PS2 D263-H

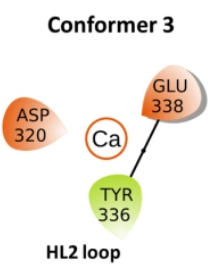

Conformer 1

Conformer 2

Conformer 3
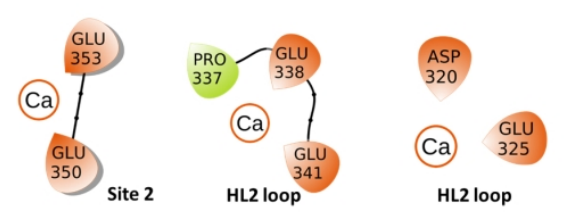

Figure 9

$169 \times 164 \mathrm{~mm}(300 \times 300$ DPI $)$ 


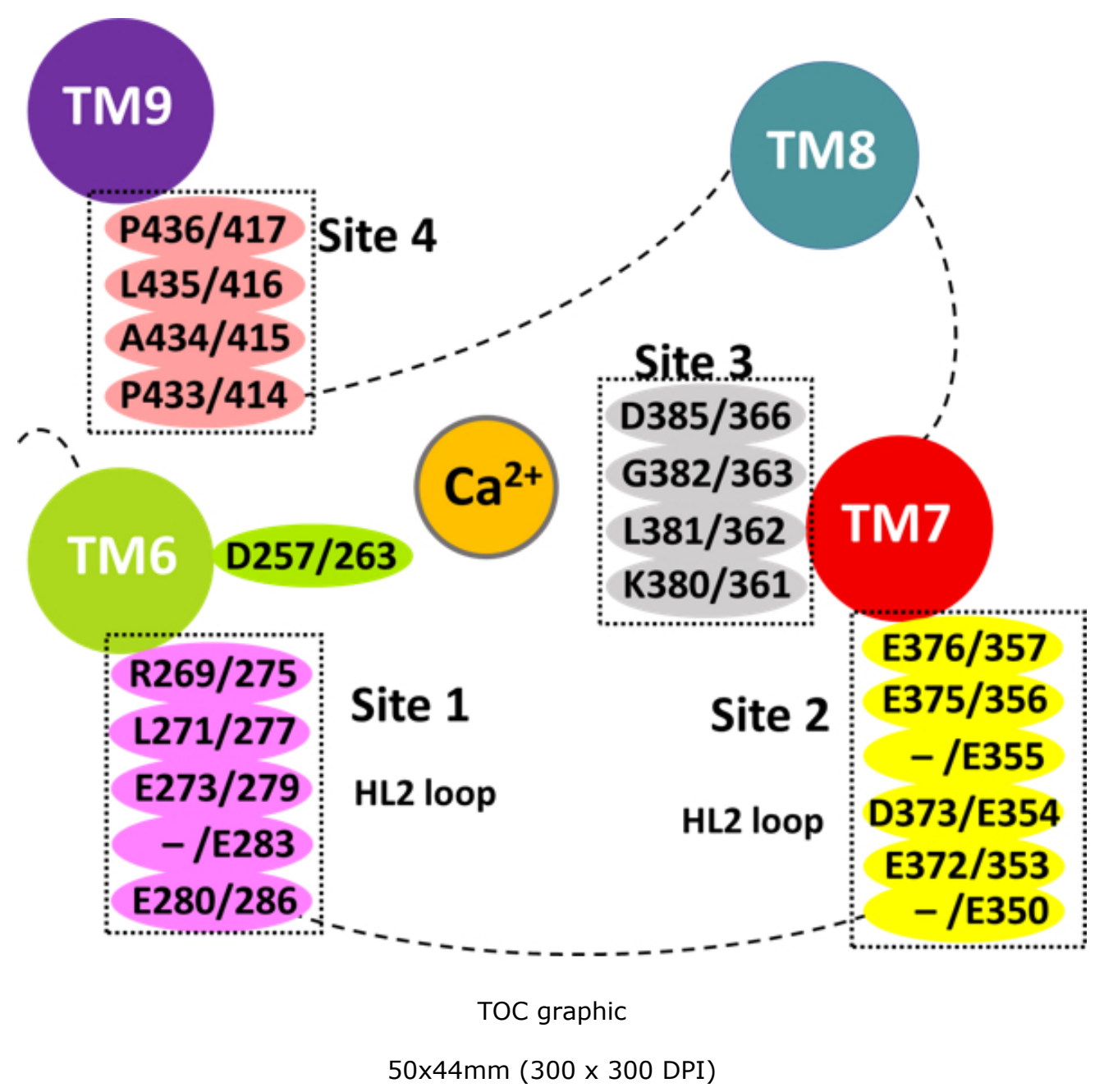

